\title{
The Mechanical Properties and Fracture Behaviour of Epoxy-Inorganic Micro- and Nano-Composites
}

\author{
A.J. Kinloch and A.C. Taylor \\ Department of Mechanical Engineering, South Kensington Campus, Imperial College London, London \\ SW7 2AZ, U.K. \\ (a.kinloch@imperial.ac.uk; a.c.taylor@imperial.ac.uk)
}

\begin{abstract}
$\underline{\text { Abstract }}$
Hybrid materials have been formed using an epoxy polymeric matrix and a range of inorganic particles, including mica and organically-modified montmorillonites ('organoclays'), with various concentrations of the silicate modifier up to about 30wt.\% depending upon the viscosity increase induced by the presence of the silicate. Wide-angle and small-angle X-ray scattering plus transmission electron microscopy were used to identify the morphologies produced, which included particulate, intercalated and ordered exfoliated. The modulus of these composites increased with the weight fraction of silicate. The morphology had a small effect on the measured modulus; the nano-composites with the ordered exfoliated microstructure showing the highest values of the modulus for a given volume fraction of silicate. The fracture toughness, $K_{c}$, and the fracture energy, $G_{c}$, initially increased as the weight fraction of the silicate was increased, but then decreased at relatively high concentrations. The measured moduli and toughnesses were compared to theoretical predictions. The measured moduli values showed very good agreement with the predicted values, whilst the agreement for values of the measured fracture energy, $G_{c}$, with the predicted values, based upon a crack deflection toughening mechanism, were less convincing. Indeed, analysis of the fracture surfaces using scanning electron microscopy showed that the main toughening effect of the silicate particles is due plastic deformation of the epoxy matrix around the particles.
\end{abstract}

\section{$\underline{\text { Keywords }}$}

Nanocomposites

Deformation and fracture

Polymers 


\section{Introduction}

In recent years the concept of forming hybrids using polymers and inorganic materials has received a significant amount of attention. Many claims for the potential of these organic/inorganic hybrids have been made [1], but for some combinations of materials little experimental data has been produced. Many of these studies have used surface-treated silicates, or organoclays, to produce layered-silicate nano-composites, e.g. [2, 3]. A nano-composite is defined as a composite where one of the components has a dimension in the nanometre range [3]. The addition of inorganic filler to a polymer matrix can greatly increase its stiffness, especially for thermoplastic materials in the rubbery region. However, thermosetting polymers have attracted less attention, and much of the work that has been done using these materials has employed elastomeric epoxies, e.g. [4, 5]. Some studies have used rigid thermosets, e.g. $[6,7,8]$, and high-functionality epoxies $[9,10]$. However, though various authors have studied the properties of epoxy-silicate nano-composites $[11,12,13,14,15]$, there have generally been few studies comparing the properties of thermoset nano- and micro-composites [16, 17, 18].

The present paper is concerned with the mechanical properties and fracture behaviour of epoxyinorganic micro- and nano-composites and discusses how the morphology of the inorganic particles can affect the mechanical and fracture properties of the nano-composites produced. This morphology is typically described as 'particulate' (or conventional), 'intercalated' or 'exfoliated', as identified by wide-angle X-ray scattering (WAXS) [19, 20]. These microstructures are shown schematically in Figure 1. In an intercalated nano-composite, polymer chains enter the galleries between the clay platelets and increase the measured spacing. For an exfoliated structure, the clay platelets are pushed further apart, and the spacing becomes too large to measure using WAXS. Note that an exfoliated structure may be ordered or disordered as shown in Figure 1. For a particulate structure, the particles remain unchanged.

\section{Experimental}

\subsection{Materials}

The epoxy used was a diglycidylether of bisphenol A, DGEBA, (AY105, Huntsman, UK) cured using an amine hardener, polyoxypropylenediamine, (Jeffamine D230, Huntsman, UK). A range of inorganic particles was used, as shown in Table 1, comprising unmodified and organically-modified silicates. Mica is a platy potassium aluminium silicate, and was supplied with no surface treatment. The other particles are all montmorillonite (a smectite clay). These clays were supplied either untreated (Cloisite $\mathrm{Na}^{+}$) or with an organic surface treatment. Three surface-treated clays were used - Cloisite 25A is treated with dimethyl, hydrogenated tallow, 2-ethylhexyl quaternary ammonium, and Cloisite 30B is treated with methyl, tallow, bis-2-hydroxyethyl, quaternary ammonium. Finally, Nanomer I30E is treated with octadecylamine. 
Plates of epoxy composite, $6 \mathrm{~mm}$ thick, were produced as follows. The epoxy was poured into a beaker, the inorganic particles were added and the mixture was stirred using a spatula. The beaker was placed in a vacuum oven at $75^{\circ} \mathrm{C}$, and the entrapped air was removed from the resin. The vacuum was then released, and the mixture was left in the oven for 24 hours. After this time the mixture was stirred and a stoichiometric amount of hardener added. The mixture was stirred again and poured into a release-coated steel mould. The mould was placed in an oven, and the epoxy was cured for 3 hours at $75^{\circ} \mathrm{C}$ followed by 12 hours at $110^{\circ} \mathrm{C}$ [21]. The plate of epoxy was removed after cooling and machined to produce tensile dumbbell and fracture specimens according to the relevant standards [22, 23, 24].

Note that the addition of the silicates increased the viscosity of the epoxy resin and hence there was a maximum percentage inclusion of silicate, above which the viscosity of the resin was too high to be able to cast the plates to make the test specimens. For the Cloisite 30B and 25A, a maximum of $15 \mathrm{wt} . \%$ of silicate could be used. The maximum addition of Nanomer I30E was 10wt.\%, and of Cloisite $\mathrm{Na}^{+}$was $20 \mathrm{wt}$ \%. For the mica-modified epoxy, 30wt.\% of silicate could be used.

\subsection{Mechanical and Fracture Testing}

The tensile specimens were tested in compliance with the standards [22, 24] at a constant displacement rate of $1 \mathrm{~mm} / \mathrm{min}$, using a clip-on extensometer to measure the strain within the gauge length. The Young's modulus was calculated for each of the four replicate samples. The fracture specimens were tested at a constant displacement rate of $1 \mathrm{~mm} / \mathrm{min}$. Both compact tension (CT) and single-edge notch bend (SENB) tests were performed. Four replicate samples were used in each case and the fracture toughness, $\mathrm{K}_{\mathrm{c}}$, was calculated. The machined notch was sharpened by drawing a new razor blade across the notch tip prior to testing [23]. Note that the data produced were compared to data from specimens where a natural crack had been tapped into the specimen, and the $\mathrm{K}_{\mathrm{c}}$ values using both techniques were found to be identical within experimental error. Also there was no significant difference between the data from the CT and the SENB test geometries.

\subsection{Characterisation}

Wide-angle X-ray scattering (WAXS) was performed using $\mathrm{CuK} \alpha(\lambda=1.542 \AA)$ radiation over a range of $2 \theta$ from 3 to $25^{\circ}$, with some samples being analysed from $2 \theta=1$ to $25^{\circ}$, at a scanning speed of $0.48^{\circ} / \mathrm{min}$ and a step size of $0.04^{\circ}$. Samples of the composites were cut from the plates produced and clamped in the diffractometer. The silicate powder samples were mounted on a single-crystal silicon sample disc using pressure-sensitive tape.

WAXS texture analysis was performed using plates of mica-epoxy micro-composite to investigate the orientation of particles within the composite plates. Samples $100 \mathrm{~mm}$ square by $6 \mathrm{~mm}$ thick were used. A constant diffraction angle was employed, corresponding to a strong peak in the silicate WAXS spectrum. The sample was tilted and rotated, and the intensity of the diffraction peak was measured. The intensity data were plotted against the platelet orientation on a pole plot. Once data 
had been obtained from the surface of the sample, the surface of the sample was machined away and another scan was performed. This process was repeated several times, allowing the variation of the orientation of the silicate platelets with depth into the sample to be investigated.

Small-angle X-ray scattering (SAXS) was also performed on some of the nano-composite samples using $\mathrm{CuK} \alpha$ radiation. Thin sheets of the composites, about $1 \mathrm{~mm}$ thick, were cast in steel moulds and cured as described above. The data were corrected for background and detector response, and azimuthally averaged to the one-dimensional form of intensity versus the scattering wavevector, $\mathrm{q}$, where $\mathrm{q}=\left(4 \pi / \lambda_{\mathrm{w}}\right) \sin \theta$; where $\lambda_{\mathrm{w}}$ is the wavelength and $\theta$ is the diffraction angle [25].

Laser light scattering (LLS) was used to measure the particle size of the silicates prior to the formation of the epoxy composites. The particles were dispersed in a solvent (e.g. water, hexane or ethanol) and WAXS was used to check that the solvent did not swell the particles. The aspect ratio of the particles was also determined; using the apparent density of the particles in the solvent measured using density bottles.

Scanning electron microscopy (SEM) was used to investigate the size and shape of the silicate particles prior to incorporation into the epoxy resin. SEM was also used to observe the fracture surfaces of the SENB samples after testing. Samples were sputter-coated with a thin layer of gold prior to observation. Transmission electron microscopy (TEM) was also used to investigate the microstructure of the composites. Microtomed samples were used for these studies, and these were mounted on copper grids and coated with a thin layer of carbon prior to mounting in the microscope.

The surface roughness of the fracture surfaces was measured using stylus profilometry. A stylus with a tip radius of $2.5 \mu \mathrm{m}$ was drawn across the surface at a constant speed for a set distance. Five measurements with a length of $4 \mathrm{~mm}$ were performed perpendicular to the direction of the crack growth, and the average roughness, $R_{a}$, of the line profiles was calculated.

The glass transition temperatures of the cured samples were measured using differential scanning calorimetry (DSC), over a temperature range of 20 to $100^{\circ} \mathrm{C}$ with a scan rate of $20^{\circ} \mathrm{C} / \mathrm{min}$.

\section{Theoretical}

\subsection{Introduction}

The experimental data can be compared to analytical models of the modulus and fracture energy of particle-modified polymers. Hence the relevant models used, and the assumptions made, will be outlined. 


\subsection{Prediction of Tensile Modulus}

\subsubsection{Introduction}

There are many theoretical models that may be used to predict the moduli of particle-modified polymers, e.g. [26, 27, 28]. The most commonly used models are the rule of mixtures, Halpin-Tsai and Mori-Tanaka relationships. Other models are summarised in a review paper by Ahmed \& Jones [29]. Note that these models make a number of assumptions. They assume that the matrix and the particles are linear-elastic, isotropic and that there is perfect bonding between the particles and the matrix. They also assume that the particles are (where applicable) uniform in their aspect ratio and perfectly aligned with the applied load. The models also ignore any agglomeration and particle-particle interactions.

These predictive models use the volume fraction of particles or of the silicate. For the silicates with no organic surface treatment, the volume fraction can be calculated using the densities of the epoxy matrix and the silicate, and the volume fraction of particles is equal to that of the silicate. The models assume that the composite is composed of two phases: the matrix and the particles. Hence for the surface-treated silicates, the volume fraction of silicate used in these predictions is the volume of the silicate without the surfactant. The surfactant will have a modulus that is much lower than that of the silicate; hence the surfactant does not stiffen the matrix, and can be assumed to have a modulus approximately equal to that of the epoxy. The weight fraction of surfactant can be calculated from thermogravimetric analysis data [30] or from the manufacturers' quoted data [31] on the weight loss on ignition.

It should be noted that intercalation of polymer into the galleries of a silicate particle will change both the aspect ratio, the modulus and the volume fraction of the particles. The volume fraction of particles can be calculated assuming that the intercalated polymer becomes part of a composite particle. The modulus of such a composite particle, parallel to its platelets, can be estimated by the rule of mixtures, as used by Brune \& Bicerano [32] and Fornes \& Paul [18]:

$$
E_{\text {particle }}=V_{\text {silicate }} E_{\text {silicate }}+\left(1-V_{\text {silicate }}\right) E_{\text {epoxy }}
$$

where $\mathrm{V}_{\text {silicate }}$ is the volume fraction of silicate, $\mathrm{E}_{\text {silicate }}$ is the modulus of montmorillonite, and $\mathrm{E}_{\text {epoxy }}$ is the modulus of the epoxy. Here the surfactant is again assumed to have the same modulus as the epoxy. Hence the composite particle modulus, $\mathrm{E}_{\text {particle, }}$ is used in place of the silicate modulus in the modulus prediction models when intercalation occurs.

\subsubsection{Modified Rule of Mixtures}

The rule of mixtures provides an upper bound for the modulus, $E_{c}$, of composite materials. This model assumes that the material is a continuous fibre composite, where the fibres are unidirectionally-aligned parallel to the direction of loading:

$$
E_{c}=V_{f} E_{f}+\left(1-V_{f}\right) E_{m}
$$

where $V_{f}$ is the volume fraction of fibres, and $E_{f}$ and $E_{m}$ are the moduli of the fibres and matrix respectively. 
However, the stiffening efficiency of short fibres or particles is much lower than that of continuous fibres. Hence a modified rule of mixtures is commonly used for short-fibre composites, and has been shown to agree well with experimental results [33]. The rule of mixtures relationship is modified [33] to include a correction factor, $\mu_{\mathrm{t}}$ :

$$
E_{c}=\mu_{t} V_{f} E_{f}+\left(1-V_{f}\right) E_{m}
$$

This correction factor is given by Cox [34]:

$$
\mu_{t}=1-\frac{2}{\beta l} \tanh \left(\frac{\beta l}{2}\right)
$$

where $l$ is the length of the particles (i.e. the particle diameter for circular plate-like particles), and $\beta$ is given by:

$$
\beta=\left(\frac{2 G_{m}}{E_{f} r^{2} \ln (x / r)}\right)^{\frac{1}{2}}
$$

where $G_{m}$ is the shear modulus of the matrix, $r$ is the fibre radius and $x$ is the interfibre spacing. For plate-like particles, it can be assumed that $r$ equals half the particle thickness. The value of $\mathrm{x} / \mathrm{r}$ can be calculated by assuming that the particles are distributed in a face-centred cubic arrangement, and hence $\mathrm{x} / \mathrm{r}$ is related to the volume fraction by:

$$
\frac{x}{r}=\left(\frac{2}{\sqrt{3}} \frac{\pi}{V_{f}}\right)^{\frac{1}{2}}
$$

The shear modulus can be calculated from the modulus and Poisson's ratio of the matrix, $v_{\mathrm{m}}$, using the standard expression:

$$
G_{m}=\frac{E_{m}}{2\left(1+v_{m}\right)}
$$

In the present work the value of the correction factor, $\mu_{\mathrm{t}}$, is calculated to be around 0.3 for the micamodified epoxy and around 0.04 for the clay-modified epoxy over the range of volume fractions of interest.

The above analyses assume that the short fibres or particles are aligned parallel to the loading direction. When this is not the case, as in the present work, then a second correction factor, $\mu_{0}$, may be introduced [33]. Hence the modified rule of mixtures can be written as:

$$
E_{c}=\mu_{o} \mu_{t} V_{f} E_{f}+\left(1-V_{f}\right) E_{m}
$$

The value of $\mu_{0}$ depends on the degree of orientation of the particles, and has been calculated by Krenchel [35]. For a unidirectional lamina then $\mu_{0}=1$ when it is tested parallel to the fibre direction, and $\mu_{0}=0$ when tested perpendicular. For a three-dimensional random orientation, as in the present work, then $\mu_{0}=0.2[35,36]$. 


\subsubsection{Halpin-Tsai Model}

An alternative model to predict the modulus of particle-modified polymers comes from work by Halpin and co-workers [27, 37]. This model again assumes that the particles are aligned with the loading direction. The Halpin-Tsai model gives the modulus of the composite as a function of the modulus of the polymer and of the particles, but also as a function of the aspect ratio by the inclusion of a shape factor. The predicted composite modulus is:

$$
E_{c}=\frac{1+\zeta \eta V_{f}}{1-\eta V_{f}} E_{m}
$$

where $\zeta$ is the shape factor, and:

$$
\eta=\left(\frac{E_{f}}{E_{m}}-1\right) /\left(\frac{E_{f}}{E_{m}}+\zeta\right)
$$

In this theory the disk-like platelets are treated as rectangular. Halpin and Tsai noted that the value of $\zeta$ must lie between zero and infinity. Indeed, if $\zeta=\infty$ then equation 9 reduces to the rule of mixtures (equation 2), and if $\zeta=0$ then it reduces to the inverse (or transverse) rule of mixtures.

Halpin and Tsai suggested that the value of $\zeta$ correlated with the geometry of the reinforcing phase, especially with the aspect ratio (w/t) of the particles, where $w$ is the length of the particle and $t$ is its thickness. By comparison of the predictions with the results of a finite-element analysis, Halpin and Kardos [38] suggested that a shape factor of $\zeta=2 \mathrm{w} / \mathrm{t}$, is used for calculating the modulus of a polymer with the particles aligned with the loading direction, $\mathrm{E}_{/ /}$. In the present work, this will be referred to as the 'Halpin-Tsai parallel' model. For the modulus perpendicular to the loading direction, $\mathrm{E}_{T}$, they recommended using $\zeta=2$.

However, work by van Es [39] has shown that the value of $\zeta=2 \mathrm{w} / \mathrm{t}$ is too high for most particlemodified polymers. By comparison with the Mori-Tanaka model, discussed in section 3.4.2 below, van Es showed that the use of the Halpin-Tsai model with $\zeta=2 \mathrm{w} / 3 \mathrm{t}$ gives good agreement with the MoriTanaka predictions.

These models assume that the particles are aligned. Polymers with a random orientation of particles would be expected to give lower modulus values. Van Es et al [17] have used laminate theory to show that the modulus of a particle-modified polymer with a random orientation of particles is given by:

$$
E_{c}=0.49 E_{/ /}+0.51 E_{T}
$$

where the parallel and transverse moduli, $\mathrm{E}_{/ /}$and $\mathrm{E}_{T}$, are calculated using the Halpin-Tsai model with $\zeta=2 \mathrm{w} / 3 \mathrm{t}$ for $\mathrm{E}_{/ /}$and $\zeta=2$ for $\mathrm{E}_{T}$. In the present work, this will be referred to as the 'Halpin-Tsai random' model. 


\subsubsection{Mori-Tanaka Model}

The Mori-Tanaka model is also commonly used for predicting the modulus of particle-modified polymers $[12,18]$. Here the particles are treated as ellipsoidal (either fibre-like or plate-like) with a constant aspect ratio, and are assumed to be aligned. When the particles are plate-like and aligned with their long axis parallel to the loading direction, then the composite modulus is given by:

$$
E_{/ /}=\frac{E_{m}}{1+V_{f}\left(A_{1}+2 v A_{2}\right) / A}
$$

where $A, A_{1}$ and $A_{2}$ are functions of the aspect ratio and volume fraction of the particles, plus the Young's modulus and Poisson's ratio of the matrix and particles. The full set of equations required to calculate the predicted modulus, including the components of the Eshelby tensor, are given by Tandon and Weng [40]. In the present work, this model will be refereed to as the 'Mori-Tanaka parallel' model.

The modulus perpendicular to the plane in which the platelets are aligned is given by:

$$
E_{T}=\frac{E_{m}}{1+V_{f}\left(-2 v_{m} A_{3}+\left(1-V_{f}\right) A_{4}+\left(1-V_{f}\right) A_{5} A\right) / 2 A}
$$

where $A, A_{3}, A_{4}$ and $A_{5}$ are functions of the aspect ratio and volume fraction of the particles, plus the Young's modulus and Poisson's ratio of the matrix and particles. Hence the modulus of a polymer with a random orientation of particles can be calculated using the laminate approximation of van Es et al, i.e. using equation 11. This will be referred to as the 'Mori-Tanaka random' model. When intercalation occurs, then equation 1 is used to calculate the effective particle modulus, as above.

\subsection{Prediction of Fracture Energy}

The addition of rigid, impenetrable particles to an epoxy polymer would be expected to increase the fracture energy, and the measured values can be compared to the analytical model predictions from the theory developed by Faber and Evans [41]. These predictions describe the toughening effect caused by the deflection of the crack front when it reaches a particle. Faber and Evans modelled these predictions in the form of the relative fracture energy of the modified material (which is defined as the fracture energy of the modified material normalised to that of the unmodified material) for sphere-, rod- and plate-shaped particles, as a function of the volume fraction and aspect ratio of the particle.

The Faber and Evans analysis [41] uses a crack deflection model. When an advancing crack encounters a particle, there is an initial deflection of the crack that tilts the crack out of its advancing plane. Subsequent twisting and tilting of the crack occurs as the deflected crack encounters further particles. The increased area of the fracture surface causes a small increase in the measured fracture toughness. However, the deflected crack is now subjected to mixed-mode loading. The tilted crack experiences mode I (tensile) and mode II (in-plane shear) loading, while the twisted crack experiences mode I and mode III (anti-plane shear) loading. It is well known that fracture under mode II and mode III loading requires more energy than in mode I, and hence the local mode-mix increases the measured fracture energy in a nominally mode I fracture test. 
In previous work by the authors [42], the toughening effect of particles in a polymer matrix has been compared to predictions using the Faber and Evans model. In that work Kinloch and Taylor discussed particle-modified thermosetting polymers in some detail. They used a range of silicate particles, including mica, and found good agreement between the predictions and the experimental data for small aspect ratios. However, the agreement was relatively poor when the particle aspect ratio was high. In these cases the model over-predicted the composite fracture energy.

In the present work, the fracture energy, $G_{c}$, of the composite samples can be calculated from the measured fracture toughness, $K_{c}$, and modulus, $E_{c}$, to allow comparison with the Faber and Evans predictions using [43]:

$$
G_{c}=\frac{K_{c}^{2}\left(1-v^{2}\right)}{E_{c}}
$$

where $v$ is the Poisson's ratio. It can be assumed that the Poisson's ratio for these materials is approximately equal to 0.35 . These experimental data can then be compared to the theoretical predictions using the equations which are given in full in the Faber and Evans paper [41].

\section{Results}

\subsection{Introduction}

Analysis of the wide-angle X-ray scattering (WAXS) data enables the microstructure of the composites to be inferred, i.e. whether they are exfoliated, intercalated or particulate. In some cases additional microstructural information was obtained using small angle X-ray scattering, transmission electron microscopy and WAXS texture analysis. The orientation of the particles was observed to be random in all cases using scanning electron microscopy. The moduli and fracture toughnesses of the micro- and nano-composites were also measured.

\subsection{Particle Size Studies}

The size and aspect ratio of the silicate particles prior to incorporation into the epoxy were investigated using laser light scattering (LLS) and scanning electron microscopy (SEM). Different techniques of particle size determination give different mean values [44]. In the general case, the mean diameter, D, can be calculated using:

$$
D(m, n)=\sqrt[m-n]{\sum d^{m} / \sum d^{n}}
$$

where $d$ is the apparent diameter of each particle. The values of $m$ and $n$ correspond to the type of measurement used to calculate the particle diameter, D. For example an image analysis method based on measurement of the surface area (which has a $\mathrm{d}^{2}$ dependence so $\mathrm{m}=2$ ) and division by the number of particles (which has a $\mathrm{d}^{0}$ dependence so $\mathrm{n}=0$ ) would give a calculated mean diameter written as $\mathrm{D}(2,0)$. 
Laser light scattering is based on the assumption that the particles are spherical and of equal size. However, it has been shown that the actual particle size distribution follows a normal distribution on linear versus logarithmic axes. Laser light scattering measures $\mathrm{D}(4,3)$, the volume or mass moment mean diameter, and $\mathrm{D}(3,2)$, the surface area moment mean diameter. The mean diameters measured by LLS are analogous to moments of inertia, showing how the mass or surface area is distributed over the volume [44]. Perfectly spherical particles would give the same value of $\mathrm{D}(4,3)$ and $\mathrm{D}(3,2)$. Where the particles are not spherical the true mean diameter lies between these two values. For plate-like particles the ratio of $\mathrm{D}(4,3)$ to $\mathrm{D}(3,2)$ indicates how similar the width and length of each particle are. A ratio of 2:1 indicates that the particles are circular, i.e. equal in width and length. For all the particles used in the present work the ratio of $\mathrm{D}(4,3)$ to $\mathrm{D}(3,2)$ was found to be close to $2: 1$, hence the particles can be assumed to be circular discs.

As laser light scattering assumes spherical particles, the measured concentration of plate-like particles in the solvent will be higher than the real concentration of particles. The real concentration may be calculated using the apparent density of the wet powder in the solvent used. Indeed, the aspect ratio of plate-like particles is given by the ratio of the measured to the real concentration.

The results of the laser light scattering measurements are shown in Figure 2 and Table 1. The mica has a mean diameter of about $50 \mu \mathrm{m}$ and an aspect ratio of fifteen. This compares well with the manufacturer's quoted mean diameter of $55 \mu \mathrm{m}$ and aspect ratio of fourteen. The particle size was confirmed by scanning electron microscopy, as shown in Figure 3. A mean diameter of $25 \mu \mathrm{m}$ was measured using LLS for the Cloisite $\mathrm{Na}^{+}$, and of $10 \mu \mathrm{m}$ for the other clays. Again, SEM and image analysis confirmed that these values are reasonable and shows that the Cloisite $\mathrm{Na}^{+}$particles are definitely larger than those of the Cloisite 25A, see Figure 3. An aspect ratio of approximately four was measured for all the clays.

\subsection{Wide-Angle X-ray Scattering Studies}

The peaks observed in the WAXS data represent one of two types of crystallographic feature, either a $00 l$ basal reflection or an $h k 0$ diffraction band [45]. The positions of the $00 l$ reflections indicate the distance between the silicate platelets, and hence the spacing will vary when water or polymer molecules lie between the platelets. The $h k 0$ diffraction band positions remain fixed for a given silicate, as they indicate the internal structure of the platelets. Hence the position of the 001 reflection can be used to calculate the distance between platelets, the d-spacing, and thus indicate the microstructure of the composite. Should the position of the 001 peak be outside the detection range of the diffractometer, then the d-spacing can be calculated using the position of the second order (002) or third order (003) reflections. The theoretical relationship between these peaks shows that the 002 reflection occurs at half the 001 spacing, and the 003 reflection occurs at one third of the 001 spacing [45]. 
In interpreting the WAXS data, the present work uses the convention that an exfoliated morphology is indicated by a WAXS spectrum with no discernible $00 l$ peaks. If the $00 \mathrm{l}$ peaks for the silicate and the epoxy/silicate composite occur at the same position then the morphology is considered to be particulate. An increase in the measured spacing between the silicate platelets is assumed to indicate an intercalated morphology. Note that it is difficult to discern accurately the degree of order of the silicate platelets using WAXS alone [19, 20]. Although a specific type of surface-treated silicate may form an exfoliated structure at low percentage inclusion in a polymer matrix, when large concentrations are used the silicate may have insufficient room to exfoliate fully, and hence a more intercalated structure may be formed.

The WAXS analysis of the unmodified epoxy showed a broad peak, see Figure 4, with a maximum at approximately $2 \theta=18^{\circ}$. These data indicate that the cured material has an amorphous structure, as expected for a thermosetting polymer.

The WAXS results showed that the mica has a 001 peak at $10 \AA$ and a 002 peak at $5 \AA$, see Figure 4. These values agree with the theoretical prediction that the 002 spacing is half the 001 spacing [46], and the spacings agree exactly with the known reflections for muscovite mica [47, 48]. The positions of the 001 peaks for the mica and the mica/epoxy micro-composite are identical, as are the positions of the 002 peaks, and hence the mica-epoxy specimens possess a particulate morphology.

The untreated clay, Cloisite $\mathrm{Na}^{+}$, shows a 001 peak at a d-spacing of $12.2 \AA$. The manufacturer quotes a d-spacing of $11.7 \AA$ [31], which may indicate some water absorption has occurred during storage. Thus the composites show a particulate morphology, as the position of the peaks for the clay and the composites were identical.

The Nanomer I30E-modified epoxy shows an exfoliated morphology as identified by WAXS, see Figure 5. The WAXS data for the nano-composite show no discernible peaks, whilst the silicate has a d-spacing of approximately $25.4 \AA$. The manufacturer does not quote a d-spacing for this surfacetreated silicate [49]. The peak at $2 \theta \approx 20^{\circ}$, equivalent to $4.5 \AA$, relates to the internal structure of the clay platelet and will occur in the WAXS spectrum of all materials containing montmorillonite. This value agrees exactly with the published values for the 020 and 110 reflections of montmorillonite [45]. Note that the broad amorphous peak at angles of $2 \theta$ greater than $11^{\circ}$ results from the pressure-sensitive tape used to mount powders in the diffractometer as well as from the surfactant on the clay platelets.

The Cloisite 25A shows a WAXS peak at a d-spacing of approximately $18.9 \AA$, as shown in Figure 6. This compares well with the manufacturer's quoted value of $18.6 \AA$ [31]. This comes from the 001 reflection, and no lower order (002 or 003) reflections are visible. For the 25A-modified epoxy, the 001 peak was observed at a spacing of $31.3 \AA$ and the 002 peak was observed at $15.6 \AA\left(2 \theta=2.8^{\circ}\right.$ and $5.7^{\circ}$ respectively, as shown in Figure 6), indicating that the morphology is intercalated. As expected 
from the literature [45], the 002 peak has a much lower intensity than the 001 peak. Note that the nanocomposite data also show a very small peak at $2 \theta=8.5^{\circ}$, equivalent to a spacing of $10.4 \AA$, due to the 003 reflection.

WAXS of the Cloisite 30B showed a 001 peak with a d-spacing of $18.4 \AA$, which compares very well with the manufacturer's quoted value of $18.5 \AA$ [31]. For the 5wt.\% Cloisite 30B nano-composite, 001 and 002 peaks are observed at spacings of 39.6 and $19.3 \AA$ respectively, see Figure 7. Hence the morphology of the Cloisite 30B-modified epoxy is intercalated, as the d-spacing increases from 18.4 to 39.6A, as shown by the 001 data. This is confirmed by the second order reflection (002) data. As the percentage of clay is increased, the d-spacings decrease slightly, the 001 and 002 peaks moved to spacings of 38.7 and $18.9 \AA$ respectively for $10 \mathrm{wt} . \%$ of silicate. Note that the d-spacings of the Cloisite 30B-modified composites are greater than those of the 25A-modified materials, and hence the Cloisite 30B-modified nano-composite morphology is closer to being exfoliated than that of the Cloisite 25Amodified nano-composite.

The measured position of the peaks, and hence the spacing between the platelets, changes slightly as the loading of silicate is increased. For the Cloisite 30B-epoxy nano-composites the spacings vary from $39.6 \AA$ at low loadings to $37.4 \AA$ when $15 \mathrm{wt}$.\% of clay is used. The Cloisite $25 \mathrm{~A}$-epoxy composites show the same trend, a reduction of about $2 \AA$ between low and high loadings. These changes are not really significant when compared to the initial increase of over $20 \AA$ due to intercalation of the epoxy resin.

\subsection{Small-Angle X-ray Scattering Studies}

Small-angle X-ray scattering (SAXS) was used to investigate the morphology of the nano-composite with 5wt.\% Nanomer I30E, as this nano-composite showed an exfoliated morphology using WAXS. Samples of unmodified epoxy and epoxy with 5wt.\% Cloisite 30B were used as control samples. The unmodified epoxy showed an amorphous structure, and the data collected were used as the background correction for the composite samples. The composite data are shown in Figure 8, where the SAXS intensity is plotted against the scattering vector. In this figure the Lorentz correction is used, i.e. the intensity used is $I^{*} q^{2}$ where $I$ is the measured intensity and $q$ is the scattering vector, which makes the relatively weak broad peak shown by the nano-composite with 5wt.\% Nanomer I30E clearer [25]. This value can be converted to the intergallery spacing using $d=2 \pi / q_{p}$ where $d$ is the $d$-spacing and $q_{p}$ is the peak position.

The Cloisite 30B-epoxy nano-composite showed a peak at a scattering vector of $q_{p}=0.164 \AA^{-1}$, and hence at an intergallery spacing of $38.3 \AA$. This agrees well with the WAXS value of $39.6 \AA$, as shown in Table 3, and confirms that the structure is intercalated. The nano-composite with 5wt.\% Nanomer I30E showed a peak centred at $\mathrm{q}_{\mathrm{p}}=0.06 \AA^{-1}$, equivalent to an intergallery spacing of $102 \AA$, which agrees well with observations in the literature [50]. Hence, though the WAXS data indicated an 
exfoliated structure the morphology is ordered, rather than disordered, see Figure 1. If a disordered structure had been present, then the SAXS would have shown no peaks. Therefore the Nanomer I30Eepoxy nano-composites show an ordered exfoliated microstructure.

\subsection{WAXS Texture Analysis}

WAXS texture analysis was used to determine the extent of particle orientation in the epoxy composite plates from which the mechanical and fracture test specimens were cut. The specimen is mounted in a holder such that it can be rotated in its own plane about an axis normal to the surface and about a horizontal axis [51]. The diffraction angle of the X-ray beam is set to a constant value, equal to that of a strong peak in the WAXS spectrum of the particles. The plate is rotated and tilted, whilst maintaining a constant diffraction angle, and the intensity of the reflected signal is measured. These data are plotted on a pole figure, with contours to indicate the signal intensity. For a random distribution of particle orientations the signal intensity will be approximately constant across the whole of the pole figure. When the particles are orientated parallel to the plate surface then there will be a single sharp peak in the centre of the pole figure [51].

To provide a good signal to background ratio a relatively high loading of silicate is required. Hence a plate with $20 \mathrm{wt} . \%$ mica was used for these measurements. The diffraction pattern of this material showed a clear peak at $26.72^{\circ}$. This diffraction angle is equivalent to a spacing of $3.33 \AA$, which is the lattice plane indexed 003 [47, 48]. Hence the diffraction angle $(2 \theta)$ was set to this value prior to performing scans through the range of tilt and rotation angles. As mica cleaves along $00 \mathrm{l}$ planes then diffracting at this specific angle gives access to the orientation of the flakes. When the tilt and rotation angles are equal to zero then there is a perfect orientation of the flakes parallel to the surface of the plate.

The variation of the particle orientation with depth into the plate was investigated by analysing the surface of the plate, then machining down by a depth of 0.5 or $1 \mathrm{~mm}$ before analysing the plate again.

It should be noted that the analysis volume depends upon the penetration depth of the X-rays, which varies with the value of $2 \theta$ used. As the value of $2 \theta$ is increased, so the depth of analysis will increase. However, the depth can be calculated using a standard X-ray penetration depth analysis [51] and the absorption coefficients of the elements [51]. The number of X-rays which are absorbed by the sample, and hence which are not recorded, increases exponentially with depth. For the texture analysis a value of $2 \theta=26.72^{\circ}$ was used, and $90 \%$ of the signal comes from X-rays which penetrated no further than about $100 \mu \mathrm{m}$ into the plate. Hence the analysis depth is small compared to the machining steps used. 
The WAXS texture data from the surface of the plate are shown on a three-dimensional pole plot in Figure 9. The data show a large peak at the centre of the plot. The origin (centre) of these pole plots corresponds to a zero tilt and hence this corresponds to platelets that are orientated with the diffracted lattice plane $00 \mathrm{l}$ parallel to the surface of the plate. The radial direction indicates deviation from this alignment. At the edge of the pole plot the lattice planes of the particles are perpendicular to the plate surface. A flat distribution of intensities in the radial direction would indicate a random distribution of particle orientation [51]. Hence the peak at the centre of the pole plot in Figure 9 clearly shows that the particles at the surface of the plate are orientated parallel to the surface. This is expected as the plates are cast in a mould and hence the interaction of the particles in the liquid resin with the mould surfaces will tend to align the platelets parallel to the surface.

These data can also be displayed as a contour map, as shown in Figure 10a, on a twodimensional pole plot. Here the contours are set at a constant relative intensity. Hence the sharp peak is represented by contours that are close together and close to the origin. Away from the surface of the plate there is less orientation, see Figures $10 \mathrm{~b}-\mathrm{d}$, as the contours become further apart and the peak becomes less intense. Hence in the bulk of the plate the particles are not strongly orientated, but they do not show a completely random orientation as the intensities are not constant across the whole plot. This may be expected as the plates are relatively thin, being $6 \mathrm{~mm}$ in thickness, and hence some slight orientation effect would be anticipated even well away from the surface.

Note that the surface data exhibit a peak slightly decentred from the z-axis by $7.3^{\circ}$, see Figure 10a. This deviation is significant enough to indicate that the platelets at the surface are not exactly parallel to the surface, but are slightly tilted. This discrepancy is thought to result from the moulding process, as the plates are cast in a vertical mould. Hence there will be a small amount of sedimentation during curing, which leads to some tilting of the particles.

\subsection{Transmission Electron Microscopy Studies}

Transmission electron microscopy (TEM) was used to confirm the microstructure of the nanocomposites inferred from the WAXS data, and to investigate the distribution of particles through the epoxy matrix. TEM at relatively low magnifications, $\mathrm{x} 4000$ for example, shows that the particles are well distributed through the matrix.

Note that the TEM images only show a small area of the sample, approximately 0.4 by $0.5 \mu \mathrm{m}$ for the image shown in Figure 11 for example. These dimensions should be compared with the particle size, which was $10 \mu \mathrm{m}$ diameter by $2.5 \mu \mathrm{m}$ thick, before the epoxy was added. After intercalation, the dspacing increases and so does the particle thickness. Hence the TEM image shown here will only include part of one particle. As there is some variation in the spacing between the individual platelets, as shown by the broadness of the peaks in the WAXS analysis, then complete agreement with the WAXS data cannot be expected. The WAXS uses a much larger sample volume than TEM, and hence 
the average spacings measured using WAXS can be considered to be more characteristic of the composites than those observed using TEM.

The Cloisite 25A nano-composites showed an intercalated structure, with the platelets lying parallel to each other in stacks, see Figure 11. Hence the stacked layer structure of the particles prior to addition of the epoxy is preserved, but the spacing between the platelets is increased. Analysis of the TEM images shows a range of spacings between the platelets, from about $30 \AA$ and above. These values are in very good agreement with the values measured using WAXS, where the highest intensity was recorded at a spacing of $31.3 \AA$.

The epoxy-Nanomer I30E nano-composites also showed an intercalated structure, but with a larger spacing between the platelets than observed for the other nano-composites, as shown in Figure 12. Spacings of $60 \AA$ and greater were measured from the TEM images. The TEM also showed that the individual groups were generally composed of stacks of fewer platelets for the epoxy-Nanomer I30E nano-composite than for the epoxy-Cloisite 25A nano-composite: about four platelets compared to eight for the Cloisite 25A. However, microscopy at lower magnifications showed that these stacks of platelets were arranged in agglomerates, hence roughly preserving the original particle structure. This confirms the ordered exfoliated nano-composite microstructure observed using WAXS.

\subsection{Glass Transition Temperatures Results}

The glass transition temperatures, $\mathrm{T}_{\mathrm{g}} \mathrm{s}$, for the epoxy polymer and the composites with 5 and $10 \mathrm{wt} . \%$ of silicate are shown in Table 3. The unmodified epoxy has a $\mathrm{T}_{\mathrm{g}}$ of $67^{\circ} \mathrm{C}$. The $\mathrm{T}_{\mathrm{g}} \mathrm{s}$ of the particulate composites lie within the range of $68 \pm 1^{\circ} \mathrm{C}$, and hence there is no significant effect on $\mathrm{T}_{\mathrm{g}}$ due to the addition of the non-surface-treated silicates. The intercalated and ordered exfoliated nano-composites show a small increase in the value of $T_{g}$. Generally, the value of $T_{g}$ becomes larger as the intergallery spacing increases and as the loading of surface-treated silicate is increased, as shown in Table 3. Hence the nano-composite with $10 \mathrm{wt} . \%$ of the Nanomer I30E, which possesses an ordered exfoliated morphology, exhibits the highest $\mathrm{T}_{\mathrm{g}}$ of $76^{\circ} \mathrm{C}$.

The increase in $T_{g}$ due to the addition of the surface-treated silicates, and the lack of any increase in $T_{g}$ when non-surface-treated silicates are added, indicates that the microstructure of the composites affects the $T_{g}$ of the epoxy polymer. The intercalation of the matrix polymer between the clay platelets increases the effective surface area of silicate, compared with a particulate morphology. Hence there is more interaction between the matrix and the silicate, increasing the constraint and hence increasing the value of $\mathrm{T}_{\mathrm{g}}$. Indeed, Huang et al [52] demonstrated that the addition of a high surface area silicate can increase the value of $T_{g}$ as the segments of the polymer chains close to the interface have lower mobility. It should be noted that for a thermosetting polymer, the crosslinked structure means that the polymer is already relatively constrained even without the silicate particles. Hence the 
additional constraint imposed by the presence of the particles is relatively small, and any increase in $\mathrm{T}_{\mathrm{g}}$ is also relatively small, as observed in the present work.

Comparing Tables 2 and 3 shows that as the intergallery spacing of the intercalated and exfoliated nano-composites increases so the glass transition temperature of the epoxy increases. As the intergallery spacing increases, a greater proportion of the polymer chains will lie between the platelets, hence the network is more constrained, leading to an increase in the value of $\mathrm{T}_{\mathrm{g}}$.

The increase in the glass transition temperature of the epoxy polymer with the addition of surface-treated silicates has been reported in the literature [53]. The present work has also shown that $\mathrm{T}_{\mathrm{g}}$ increases as the silicate loading increases. This is in agreement with published work by Brown et al [54] and Lee \& Jang [55] where the same explanation is invoked: namely as the silicate loading is increased, so the surface area of the silicate is increased, and hence there are more interactions between the particles and the polymer, leading to higher constraint of the polymeric chains and a higher glass transition temperature.

\subsection{Tensile Modulus Results}

A tensile modulus of 3.0GPa was measured for the unmodified epoxy polymer. The measured modulus was found to increase with an increasing proportion of silicate, see Figure 13. (It should be recalled that the addition of the silicates increased the viscosity of the epoxy resin and hence there was a maximum percentage inclusion of silicate, above which the viscosity of the resin was too high to be able to cast the plates to make the test specimens. This is marked for each type of silicate by a cross in Figures 13 and 14.) The largest increases in modulus at any given percentage inclusion by weight of silicate were given by the mica and the ordered-exfoliated clay, i.e. the Nanomer I30E-epoxy nano-composite. The other clay-modified materials showed a small increase in the measured modulus, and there was little difference between the measured values. This small increase is comparable to that achieved using rodlike wollastonite particles, but generally greater than that using hollow glass spheres [56]. Note that the standard deviations for all these data are generally less than $5 \%$ of the mean value.

\subsection{Fracture Toughness Results}

A fracture toughness, $\mathrm{K}_{\mathrm{c}}$, of $1.00 \mathrm{MPam}^{1 / 2}$ was measured for the unmodified epoxy. This is a typical value for an unmodified thermosetting polymer in the glassy region [43]. A relatively large toughening effect was observed for the mica-modified epoxy, as shown in Figure 14. For example, a $\mathrm{K}_{\mathrm{c}}$ value of $2.49 \mathrm{MPam}^{1 / 2}$ was measured using $20 \mathrm{wt} . \%$ of mica, an increase of $150 \%$ on the fracture toughness of the unmodified epoxy. Previous work has shown that this toughening effect is due to crack deflection and to plastic deformation initiated around the particles, leading to the formation of cavities [42]. Scanning electron microscopy confirmed that this mechanism also occurred in the present work. 
The material modified with the clay generally showed significantly less toughness for a given weight of added silicate than the mica micro-composites. Indeed the maximum measured value of $\mathrm{K}_{\mathrm{c}}$ was $1.63 \mathrm{MPam}^{1 / 2}$, using $10 \mathrm{wt} . \%$ of the Cloisite $25 \mathrm{~A}$ or $5 \mathrm{wt} . \%$ of the Cloisite $\mathrm{Na}^{+}$silicates. In general the measured values increased to a maximum as the silicate content was increased, and then decreased gradually. Note that the standard deviations for all these data are generally less than $10 \%$ of the mean value, which is typical for modified thermosets [42].

For the clay-modified materials, the measured fracture toughnesses are lower than for the micamodified epoxy. The lowest fracture toughnesses were measured for the Nanomer I30E-modified epoxy. This material has an exfoliated structure according to the WAXS data. Hence it should have a very high aspect ratio if the platelets were disordered. However, the SAXS and TEM analyses showed that the microstructure was actually ordered exfoliated. Hence the particles in the nano-composite have a lower aspect ratio than the Cloisite $\mathrm{Na}^{+}$particles, as the platelets may still retain their stacked-layer structure, i.e. they are not randomly distributed. In this case, they may act more like large composite particles than individual platelets, hence having a lower effective aspect ratio. This low aspect ratio gives a smaller toughening effect. Similar arguments can be used for the intercalated morphologies, where the intercalation of epoxy into the clay galleries reduces the particle aspect ratio, as discussed above, and hence reduces the toughening effect. Indeed a crude ranking of the measured fracture toughnesses of the composites (i.e. mica $>$ Cloisite $\mathrm{Na}^{+}>$Cloisite 25A $>$Cloisite 30B $>$Nanomer I30E) follows the ranking of the aspect ratios of the particles in the composites. This is discussed in greater detail later.

\subsection{Modulus \& Fracture Toughness}

The data show that the modulus increases continuously with the percentage of silicate added, see Figure 13. However, the fracture toughness data show a maximum value and then decrease, as shown in Figure 14. The modulus and fracture toughness data can be plotted against each other to yield a property map in order to highlight which silicate gives the most effective combination of properties, as shown in Figure 15. The experimental data are shown in Figure 15a, and the property map is shown schematically in Figure 15b. These data show that the mica-modified epoxy micro-composite possesses the greatest increase in both the fracture toughness and modulus.

Although the mica-epoxy micro-composite shows the greatest increase in both the fracture toughness and modulus, it should be noted that a maximum inclusion of 30wt.\% of mica could be achieved, see Figures 13 and 14, compared with only 10 or 15wt.\% for some of the surface-treated silicates. The high viscosity of the composites prevented plates being cast using higher concentrations of the surface-treated silicates. However, even for an equal percentage inclusion of silicate (for example $10 \mathrm{wt} . \%)$, it is the mica-modified epoxy which shows the highest values of the fracture toughness and modulus, as may be seen in Figures 13 and 14. 


\section{Comparison of Experimental Data and Theoretical Predictions}

\subsection{Modulus}

The predicted values of the composite moduli are compared to the experimental data in Figures 16 and 17, expressed as relative values, that is with the composite modulus divided by the epoxy-matrix modulus plotted against the percentage by volume of silicate. For the organoclay nano-composites, see Figure 17, it should be noted that the relative modulus is plotted against the volume of silicate present rather than the volume of silicate plus surfactant. This is because the surfactant on the organoclays will have a modulus approximately equal to that of the epoxy, i.e. about 3GPa, rather than equal to the silicate modulus of $172 \mathrm{GPa}$. The predicted values were calculated using the modified rule of mixtures (equation 8), the Halpin-Tsai parallel (equation 9, using $\zeta=2 \mathrm{w} / \mathrm{t}$ ), the Halpin-Tsai random (equation 11, using $\zeta=2 \mathrm{w} / 3 \mathrm{t}$ for $\mathrm{E}_{/ /}$and $\zeta=2$ for $\mathrm{E}_{\mathrm{T}}$ ), and the Mori-Tanaka parallel (equation 12) and random models.

Note that a silicate modulus of $172 \mathrm{GPa}$ has been used, as is commonly employed in the literature [12, 14, 17, 18, 57]. However, the elastic properties of clay minerals such as montmorillonite are almost unknown, as discussed by Vanorio et al [58]. This absence of modulus data is because the small grain size makes it impossible to isolate a single crystal large enough to perform measurements on. There are also large differences between the few experimental data (e.g. [58]) and theoretical predictions (e.g. [59]) that are available. Hence while these discrepancies remain unsolved, most authors assume that the modulus of montmorillonite is equal to that of muscovite mica, for which there is modulus data available [60, 61, 62], and which has a similar structure to that of montmorillonite [63].

In the predictive modelling calculations, an aspect ratio (w/t) of fifteen was used for mica, as determined by the laser light scattering and scanning electron microscopy studies. The other values required to calculate the theoretical moduli are shown in Table 4. Comparing the theoretical and experimental moduli for the mica-epoxy micro-composites shown in Figure 16a, reveals that the MoriTanaka random and Halpin-Tsai random predictions are almost identical. Further, the predictions from these two models agree well with the measured moduli at low silicate contents. However, the HalpinTsai parallel model severely over-predicts the micro-composite modulus, whilst the modified rule of mixtures severely under-predicts the modulus. These observations are in good agreement with those by van Es, who reported that the Halpin-Tsai parallel method will over-predict the measured microcomposite modulus [39]. The over-prediction is the result of the assumptions of perfect bonding between the particles and the matrix, and of the alignment of the particles with the loading direction. Neither of these assumptions applies here, as there is little or no adhesion of the epoxy matrix to the mica particles and the particles are relatively randomly orientated, as shown by the results from the WAXS texture analysis described above. The Mori-Tanaka parallel model shows the best agreement with the experimental data. 
The Cloisite $\mathrm{Na}^{+}$data are shown in Figure 16b, along with the theoretical predictions calculated using the particle aspect ratio of four, as determined by the laser light scattering and scanning electron microscopy studies. The modified rule of mixtures shows very poor agreement with the experimental data, and the modulus is actually predicted to decrease over the range of volume fractions used in the present work. Both the parallel and random versions of the Mori-Tanaka and the Halpin-Tsai models show reasonable agreement with the experimental data.

The aspect ratios of the organoclays prior to incorporation into the epoxy were approximately four in all cases, as determined from the laser light scattering and scanning electron microscopy studies. However, the aspect ratio will decrease after intercalation, as the intercalated polymer increases the thickness of the particles. The effective modulus of the particles was calculated using equation 1 , considering each particle as a composite of the silicate and polymer moduli. Again, the other values needed to calculate the theoretical moduli are shown in Table 4, and, as with previous work, it has been assumed that the modulus of the montmorillonite is equal to that of mica [18]. The predicted values of the composite moduli are shown in Figure 17a. For clarity, only the random Halpin-Tsai and MoriTanaka models are shown on this Figure. The parallel model predictions, which are not shown, predict higher moduli than the random models.

It should be noted that intercalation will affect the aspect ratio of the particles after incorporation into the epoxy, as discussed above. However, the results in Figure 17 and Table 2 show that there is relatively little effect on the measured modulus of any changes in the aspect ratio caused by intercalation, as can be seen if the Cloisite $\mathrm{Na}^{+}$-modified epoxy data are compared to those from the Cloisite 25A- and Cloisite 30B-modified materials. In general, the data lie close together and the standard deviations of many of the data points overlap, and hence it can be concluded that there is little effect of intercalation on the measured modulus of these clay-epoxy nano-composites over the range of aspect ratios reported in the present work. However, the modulus of the ordered exfoliated nanocomposites is slightly higher than the intercalated and particulate clay composites.

The data from the Nanomer I30E-modified epoxy give the highest modulus values, for a given volume of silicate, as shown in Figure 17b. The experimental data agree well with all of the predictions using the Halpin-Tsai and Mori-Tanaka models. Note that the predictions from the various models lie very close to each other due to the low aspect ratio, of unity, for the ordered exfoliated particles. These relatively high modulus values may be due to the ordered exfoliated morphology that is observed imposing extra constraint on the polymer chains, as shown by the increase in the glass transition temperature, see Table 3. There is also a larger surface area of silicate exposed to the polymer for these Nanomer I30E-modified epoxy nano-composites, as each silicate platelet is wetted by the epoxy rather than just the surface of the particles as for the Cloisite $\mathrm{Na}^{+}$. This allows more interaction to occur between the epoxy and the silicate and will provide an additional stiffening effect. The observed effect 
of the more exfoliated nano-composites giving higher modulus values has been predicted by Sheng et al [64] and by Luo and Daniel [12].

These data also show that, in general, the composite moduli are predicted fairly accurately. Of the models used to predict the modulus of the micro- and nano-composites in the present work, the Mori-Tanaka random model shows the best agreement with the experimental data.

\subsection{Fracture Energy}

\subsubsection{Introduction}

The measured fracture toughness values can be converted to fracture energies using equation 14, as the composite moduli are known. The values of the relative fracture energies are shown in Figure 18, plotted against the volume of silicate. The data show that the fracture energies increase at low volume fractions of silicate, up to about 3vol.\%, and then decline.

\subsubsection{Role of Crack Deflection}

As discussed earlier, the Faber \& Evans [41] model describes the toughening effect caused by the deflection of the crack front when it reaches a particle. Their predictions for the toughening effect of particles with aspect ratios of twelve and three, as used by Faber and Evans, are shown in Figure 18. These data show that the predicted values are much higher than the measured fracture energies at high volume fractions. However, at low volume fractions of silicate the experimental values of $\mathrm{G}_{\mathrm{c}}$ are greater than the theoretical predictions. Hence the general agreement between the theoretical and experimental data is rather poor.

The Faber and Evans analysis assumes that there is no effect of platelet diameter but that the aspect ratio of the platelets is critical in determining the fracture energy of the composite. For the micaepoxy micro-composites a particulate morphology is present and the mica particles have an aspect ratio of fifteen, see Table 1. A particulate morphology is also present for the Cloisite $\mathrm{Na}^{+}$-epoxy nanocomposites and the clay particles have an aspect ratio of four. However, an intercalated morphology increases the spacing between the platelets, see Table 2, which increases the thickness of the particles and so reduces the aspect ratio. For the intercalated Cloisite 25A- and 30B-modified nano-composites the aspect ratio is so reduced by a factor of two, to an aspect ratio of approximately two. In the case of the I30E particles, prior to formation of the Nanomer I30E-modified epoxy nano-composite, an aspect ratio of four was measured. However, the ordered-exfoliated morphology of this nano-composite leads to an increase in the d-spacing from $25 \AA$ to $102 \AA$ during composite formation, and hence the thickness of the particles increases by a factor of four, so reducing the aspect ratio to unity in the Nanomer I30Emodified epoxy nano-composite. As noted previously, the Faber \& Evans theory predicts that high aspect-ratio particles will give a greater toughening effect than those with a low aspect ratio. This is indeed the case, see Figure 18, as the maximum measured fracture energy values for the composites can be ranked: mica > Cloisite $\mathrm{Na}^{+}>$Cloisite 25A > Cloisite 30B > Nanomer I30E; and this ranking order 
is identical to that of the aspect ratio of the particles in the composites. However, the limited agreement between the theoretical and experimental data indicates that the Faber and Evans model cannot completely explain the measured toughness values. Further, if the toughening effect from the silicate being present was caused by crack deflection alone, then the fracture energy would be expected to increase continuously with the volume fraction of silicate, based upon the predictions of the Faber \& Evans [41] model. However, the experimental data clearly show a maximum value at about 3vol.\% of silicate, followed by a steady decrease in $\mathrm{G}_{\mathrm{c}}$. Thus it may be concluded that crack deflection cannot be the only toughening mechanism operating.

\subsubsection{Role of Surface Roughness}

The toughening effect predicted by Faber and Evans is due to a crack deflection mechanism caused by the particles. This crack deflection will increase the roughness of the fracture surfaces due to the tilting and twisting of the crack front. SEM was used to investigate the fracture surfaces of the composites, as shown in Figure 19. These micrographs show that there is an increase in the roughness of the fracture surfaces due to the addition of particles. Indeed, the apparent roughness of the fracture surfaces varies significantly from one composite to another: see Figures 19b to 19d for example where the micrographs are of composites which all contain 10wt.\% of silicate, but the roughness varies significantly depending upon the type of silicate employed. The effect of the addition of particles to the epoxy on the roughness of the fracture surfaces can also be seen from the scanning electron micrographs of the fracture surfaces, as a function of increasing content of silicate particles. For example, Figure 20 shows how the fracture surfaces of the Cloisite $\mathrm{Na}^{+}$samples change in appearance as the silicate content is increased. At low silicate contents, the surfaces are relatively smooth and featureless, with the rougher areas being associated with the silicate particles, see Figure 20a. As the loading is increased, the smoother areas become smaller in size, see Figure 20b for example, until the surface becomes uniformly rough, as shown in Figure 20c. For the composites with contents of 10wt.\% or above, the roughness does not appear to change very much, see Figures 20c to 20f.

The changes in roughness observed can be quantified by measuring the surface roughness, and the average roughness of the fracture surfaces of the samples was determined using stylus profilometry. The roughness of the neat epoxy sample was low, with an average roughness of $0.1 \mu \mathrm{m}$. The surface roughness of all the silicate-modified composites was greater than that of the unmodified epoxy, and the roughness increased with the volume fraction of silicate. These data are shown in Figure 21, where the measured roughness is plotted against the measured fracture energy for the micro-composites (Figure 21a) and nano-composites (Figure 21b). These data do not show a unique relationship between $G_{c}$ and roughness, as for a given fracture energy the measured roughness may be large or small depending on the volume fraction of silicate. The surface roughness can be used to confirm further that the measured toughness is not solely due to crack deflection, as indicated by the poor agreement of the measured $G_{c}$ values with the Faber \& Evans model. Now Arakawa \& Takahashi [65] and Hull [66, 67] have shown that the toughening effect due to crack deflection gives a linear relationship between the surface 
roughness and what these authors termed the specific crack extension resistance (effectively the increase in fracture energy). However, the data in Figures 21a \& b clearly do not show a linear relationship, indicating that crack deflection alone cannot explain the toughening effect.

The average roughness is plotted against the volume fraction of silicate in Figure 21c. The solid line shown is a least squares fit to the experimental data, showing that there is a linear relationship between the roughness and the silicate content. Hence the roughness is independent of the fracture energy of the micro- and nano-composites. Thus all the present evidence suggests that crack deflection alone cannot explain the toughening effect observed by the inclusion of silicates into the epoxy polymer.

\subsubsection{Role of Plastic Deformation of the Epoxy Matrix}

The particles might toughen the polymer by initiating plastic deformation of the matrix, leading to the formation of cavities, as observed in previous work [42]. Again analysis of the fracture surfaces can indicate whether this toughening mechanism is occurring. Figure 19b shows the fracture surface of the composite using $10 \mathrm{wt} . \%$ of mica. The particles of mica are relatively large, flat and smooth and hence are easy to identify. No residual epoxy is left adhering to the surface of the mica, and hence these particles appear to be poorly bonded to the epoxy matrix. Further, cavities can indeed be seen between the particles and the matrix. They are visible as the black regions in Figure 19b. It is noteworthy that these cavities are not observed in areas of the composite well away from the fracture surface. Hence the fracture process must form these cavities by debonding of the clay particle, or platelet, followed by plastic deformation of the epoxy matrix within the plastic zone ahead of the crack tip, during crack initiation and propagation. Indeed, it is most likely that the cavities are formed by the triaxial stress state that exists at the crack tip, causing the epoxy to debond from the particles and subsequent cavity growth due to plastic deformation of the epoxy matrix.

For the clay-modified materials, the measured fracture energies are lower than for the micamodified epoxy, although there is still a significant toughening effect. Considering the possible role of plastic deformation of the epoxy matrix initiated by the presence of the clay, then the fracture surfaces also show evidence for the formation of cavities and plastic deformation of the matrix for the Cloisite $\mathrm{Na}^{+}$-modified epoxy composite, see Figure19c; but in the case of the other clay nano-composites, with the intercalated and exfoliated microstructures, it was not possible to establish whether cavities are present on the fracture surfaces of the nano-composites. However, the irregular shape and size of the particles, and the roughness of the fracture surfaces, make the cavities much harder to identify for the clay-modified materials than for the mica-modified epoxy. Also, of course, the cavities are expected to be smaller for the clay composites than for the mica composites.

\subsubsection{High Volume Fractions of Silicate Particles}


At high volume fractions of silicate modifiers the toughening effect is reduced, as may be seen from Figure 18, and the fracture toughness may even decrease to below that of the unmodified epoxy in some cases. The reasons for this are not immediately apparent. However, the particles are relatively very thin, especially in the case of the intercalated and ordered exfoliated platelets, and at relatively high concentrations they may act to effectively sharpen and lengthen the crack, leading to fracture at lower loads and loss of toughness. Also, the particles are poorly bonded to the epoxy and after debonding they may act as very effective stress concentrations or micro-cracks at the tip of the crack and, again, these effects would be expected to become increasingly important as the concentration of the modifier is increased. Hence, the toughening effect of the silicate platelets would be reduced at higher volume fractions, as is observed experimentally. Finally, based upon these arguments, the ordered exfoliated particles, as seen in the Nanomer I30E-modified epoxy nano-composites, would be expected to give the most rapid decrease in toughness as the concentration of the clay is increased, since these platelets will effectively give the sharpest defects; and this is indeed reflected in the experimental results, as shown in Figure 18.

\subsubsection{Inter-particle Distance}

The presence of a maximum in the measured $G_{c}$ versus silicate content relationship indicates that there may be a critical inter-particulate distance that controls the toughening effect. This has been postulated by Zerda and Lesser [68]. The mean edge to edge inter-particulate distance, i.e. the mean uninterrupted distance between particles, is termed the mean free distance, $\lambda$, and can be calculated for plate-like particles using the following expression [69]:

$$
\lambda=\frac{4 V_{P}}{S_{P}} \frac{\left(1-V_{f}\right)}{V_{f}}
$$

where $V_{p}$ and $S_{p}$ are the volume and surface area of an individual particle respectively, and $V_{f}$ is the volume fraction of particles. The particles are assumed to be cylindrical, with a finite thickness. For the surface-modified clays, the volume and surface area were calculated for the particles in their intercalated or ordered exfoliated state. Here the particle volume includes the epoxy that is intercalated within the clay galleries, as it was shown above that the clays behave like particles rather than as individual platelets. Hence the particle volume and the volume fraction of particles for the nanocomposites, especially those of the ordered exfoliated nano-composites, are much larger than the initial volume of silicate. The fracture energy is plotted against the calculated mean free distance in Figure 22a, and the mean free distance that corresponds to the maximum fracture energy for each formulation is marked with a cross. These data show that the relationship between $G_{c}$ and $\lambda$ goes through a maximum. The fracture energy increases from the unmodified epoxy as $\lambda$ decreases, goes through a maximum and decreases as $\lambda$ becomes small. This maximum is most pronounced for the mica microcomposites.

An alternative way to look at the relationship between the fracture energy and the mean free distance is to consider the values of $\lambda$ that give the maximum fracture energies. The mean free distance 
was calculated for the volume fraction of particles that gave the highest value of $G_{c}$ for each silicate. These data are shown in Table 5. The data from the present work are shown together with data from the literature: calculated from epoxy-based nano-composites $[10,68]$ and cyanate-ester based microcomposites [42]. (Note that some data are shown as a minimum value, since data for low particle volume fractions are not available for all the composites.) These data show that there may be a critical particle volume fraction of around 3vol.\%, and an average mean free distance of around $235 \mu \mathrm{m}$, if only the well-established values are used. However, if all the values are used, the average mean free distance will be greater than $225 \mu \mathrm{m}$.

It has been proposed that the critical mean free distance [70] corresponds to either a transition from plane stress to plane strain conditions [71], or is due to the interaction of the stress field around neighbouring particles [72]. Figure 22b shows the measured fracture toughness versus the calculated mean free distance for specimens used in the present work. The diameter, $d_{y}$, of the plastic zone at the crack tip, in plane stress, can be calculated using [43]:

$$
d_{y}=\frac{1}{\pi}\left(\frac{K_{c}}{\sigma_{y}}\right)^{2}
$$

where $\mathrm{K}_{\mathrm{c}}$ is the measured fracture toughness and $\sigma_{\mathrm{y}}$ is the tensile yield stress of the material. Here the yield stress is assumed to be equal to that of the unmodified epoxy, hence $\sigma_{\mathrm{y}}=77 \mathrm{MPa}$ [73]. Should a transition from plane stress to plane strain be responsible for the maximum fracture energy, then the maximum $G_{c}$ values might be expected to occur when the mean free distance between particles, $\lambda$, equals the diameter of the plastic zone at the crack tip, $d_{y}$. The equality $d_{y}=\lambda$ is shown in Figure $22 b$, where the maximum fracture energies are marked with a cross. (Note that the fracture toughness is plotted in Figure 22b because substitution of the fracture energy, $G_{c}$, into equation 17, using equation 14, shows that $d_{y}$ depends on the modulus as well as $G_{c}$. As the modulus of the micro- and nanocomposites used in the present work varies significantly, it is not possible to calculate a unique relationship between $d_{y}$ and $G_{c}$. However, the relationship between $K_{c}$ and $d_{y}$ is unique when $\sigma_{y}$ is assumed to be constant.) It is interesting to note that most of the maximum fracture energies lie to the right of this relationship, i.e. when the mean free distance is greater than the plastic zone size. There will be a distribution of values of the mean free distance in real materials, and hence the maximum fracture energy might be predicted to occur when most pairs of particles are further apart than the critical value. Further, as the dependence of the fracture energy upon the mean free distance is relatively low over the range of $\lambda$ of interest (i.e. the narrow range of $\lambda$ in which the critical values lie), then a range of critical mean free distances would be expected. Hence, there is some evidence that there may be a critical mean free distance that corresponds to the maximum fracture energy, but further work would be required to confirm this.

\subsubsection{Summary}


The formation of micro- and nano-composites with silicates increases the fracture performance of epoxy polymer. The toughening mechanisms are a combination of crack deflection by the silicate and plastic deformation of the matrix around the silicate particles. The plastic deformation is initiated by the epoxy matrix debonding from the silicate, due to the relatively poor adhesion, which relieves the triaxial constraint at the crack tip and allows the epoxy to plastically deform.

\section{Conclusions}

Epoxy micro- and nano-composites have been prepared using a range of silicates. Both surface-treated and unmodified silicates were used, including mica and montmorillonite (clay). Various concentrations of the silicate modifier were used, up to about $30 \mathrm{wt} . \%$ depending upon the viscosity increase induced by the presence of the silicate. Laser light scattering was used to measure the size and aspect ratio of the particles prior to incorporation into the epoxy matrix. Wide-angle and small-angle X-ray scattering, plus transmission electron microscopy, were used to identify the morphologies of the composites produced, which included particulate, intercalated and ordered exfoliated microstructures. WAXS texture analysis showed that the particles were relatively randomly orientated in the composites.

The modulus of the composites was found to increase with the volume fraction of silicate added. The morphology had a small effect on the measured modulus; the nano-composites with the ordered exfoliated microstructure showing the highest values of the modulus for a given volume fraction of silicate. The measured moduli of the composites were compared to theoretical predictions using the modified rule of mixtures, the Mori-Tanaka and the Halpin-Tsai models. The agreement between the predictions using the Mori-Tanaka and the Halpin-Tsai models assuming a random arrangement of particles (as observed experimentally) and the experimental data was generally good.

The fracture toughness of the micro- and nano-composites was measured, and the fracture energy calculated using the measured moduli. The fracture energies of the composites increased at low volume fractions of silicate, then decreased as the concentration of silicate was increased further. The measured fracture energies were compared to predictions using a crack-deflection model, and agreement was found to be relatively poor. Further, the average roughness of the fracture surfaces, measured using profilometry, did not show a linear relationship with the fracture toughness. These observations indicate that the toughening effect cannot be solely attributed to crack deflection. The main toughening effect is due to debonding and subsequent plastic deformation of the epoxy polymer around the particles, as identified by scanning electron microscopy.

\section{Acknowledgements}

Ambrose Taylor is a Royal Academy of Engineering Post-Doctoral Research Fellow, and holds a Brian Mercer Postdoctoral Award for Innovation grant from the Royal Society. He would like to thank the 
Royal Academy of Engineering and the Royal Society for their support. The authors would like to thank the US Army European Research Office for their financial support, and to Nick Zafeiropoulous at the IPF in Dresden, QinetiQ, and Richard Sweeney of the Materials Department at Imperial College for their help with the X-ray scattering. Thanks also go to Huntsman and Minelco for supplying samples of the materials used, and to Anne Tarrant, Gregoire Ducotey, Peter Lee, Reza Mohammed and Bernt Johnsen for their help with the experimental work. 


\section{References}

1. J. HAY and S. SHAW, Chemistry in Britain 2001, 34 (2001).

2. A. USUKI, Y. KOJIMA, M. KAWASUMI, A. OKADA, Y. FUKUSHIMA, T. KURAUCHI and O. KAMIGAITO, J. Mater. Res. 8, 1179 (1993).

3. M. ALEXANDRE and P. DUBOIS, Mater. Sci. Eng. R 28, 1 (2000).

4. Z. WANG, J. MASSAM and T. J. PINNAVAIA, in "Polymer-Clay Nanocomposites" T. J. Pinnavaia, G. W. Beall, Eds. (John Wiley \& Sons, Chichester, 2000).

5. T. LAN and T. J. PINNAVAIA, Chem. Mater. 6, 2216 (1994).

6. X. KORNMANN, Licentiate, University of Lulea (1999).

7. X. KORNMANN, H. LINDBERG and L. A. BERGLUND, Polymer 42, 1303 (2001).

8. C. ZILG, R. MULHAUPT and J. FINTER, Macromolecular Chemistry and Physics 200, 661 (1999).

9. O. BECKER, R. VARLEY and G. SIMON, Polymer 43, 4365 (2002).

10. C. CHEN and D. CURLISS, SAMPE J. 37, 11 (2001).

11. W. LIU, S. V. HOA and M. PUGH, Composites Sci. Tech. 65, 307 (2005).

12. J.-J. LUO and I. M. DANIEL, Composites Sci. Tech. 63, 1607 (2003).

13. H. MIYAGAWA, M. J. RICH and L. T. DRZAL, J. Polym. Sci. B: Polymer Phys. 42, 4384 (2004).

14. H. MIYAGAWA, M. J. RICH and L. T. DRZAL, J. Polym. Sci. B: Polymer Phys. 42, 4391 (2004).

15. H. MIYAGAWA and L. T. DRZAL, J. Adhesion Sci. Tech. 18, 1571 (2004).

16. A. J. KINLOCH and A. C. TAYLOR, J. Mater. Sci. Lett. 22, 1439 (2003).

17. M. VAN ES, F. XIQIAO, J. VAN TURNHOUT and E. VAN DER GIESSEN, in "Specialty Polymer Additives: Principles and Applications" S. AL_MALAIKA, A. GOLOVOY, C. A. WILKIE, Eds. (Blackwell Science Ltd, Oxford, 2001).

18. T. D. FORNES and D. R. PAUL, Polymer 44, 4993 (2003).

19. R. A. VAIA, in "Polymer-Clay Nanocomposites" T. J. Pinnavaia, G. W. Beall, Eds. (John Wiley \& Sons, Chichester, 2001) pp. 229.

20. R. A. VAIA and E. P. GIANNELIS, Macromolecules 30, 8000 (1997).

21. X. KORNMANN, H. LINDBERG and L. A. BERGLUND, Polymer 42, 4493 (2001).

22. ISO-527-1, "Plastics - Determination of Tensile Properties - Part 1: General Principles" (ISO, Geneva, 1993).

23. BS-ISO-13586, "Plastics - Determination of Fracture Toughness (Gic and Kic) - Linear Elastic Fracture Mechanics (LEFM) Approach" (BSI, London, 2000).

24. ASTM-D638, "Standard Test Method for Tensile Properties of Plastics" (ASTM, West Conshohocken, 2001).

25. N. E. ZAFEIROPOULOS, Personal Communication (2003).

26. $\quad$ L. E. NIELSEN, J. Appl. Polymer Sci. 10, 97 (1966). 
27. J. C. HALPIN and N. J. PAGANO, J. Composite Mater. 3, 720 (1969).

28. E. H. KERNER, Proc. Phys. Soc. B 69, 808 (1956).

29. S. AHMED and F. R. JONES, J. Mater. Sci. 25, 4933 (1990).

30. A. E. TARRANT, PhD, Imperial College London (2004).

31. SOUTHERN CLAY PRODUCTS, http://www.nanoclay.com/ (2002).

32. D. A. BRUNE and J. BICERANO, Polymer 43, 369 (2002).

33. D. HULL, "An Introduction to Composite Materials", Cambridge Solid State Science Series (Cambridge University Press, Cambridge, ed. 1, 1981).

34. H. L. COX, Brit. J. Appl. Phys. 3, 72 (1952).

35. H. KRENCHEL, "Fibre Reinforcement" (Akademisk Forlag, Copenhagen, 1964).

36. F. L. MATTHEWS and R. D. RAWLINGS, "Composite Materials : Engineering and Science" (Chapman \& Hall, London, 1994).

37. J. C. HALPIN, J. Composite Mater. 3, 732 (1969).

38. J. C. HALPIN and J. L. KARDOS, Polym. Eng. Sci. 186, 344 (1976).

39. M. VAN ES, A Comparison of Polymer-Clay Nanocomposites with Conventional Composites, Nanocomposites 2000, Brussels, Belgium (Emap Maclaren, 2000).

40. G. P. TANDON and G. J. WENG, Polymer Composites 5, 327 (1984).

41. K. T. FABER and A. G. EVANS, Acta Metallurgica 31, 565 (1983).

42. A. J. KINLOCH and A. C. TAYLOR, J. Mater. Sci. 37, 433 (2002).

43. A. J. KINLOCH, "Adhesion and Adhesives : Science and Technology" (Chapman \& Hall, London, 1987).

44. A. RAWLE, “Basic Principles of Particle Size Analysis” (Malvern Instruments, UK).

45. D. M. C. MACEWAN, in "The X-Ray Identification and Crystal Structures of Clay Minerals" G. Brown, Ed. (Mineralogical Society, London, 1961).

46. G. W. BRINDLEY, in "The X-Ray Identification and Crystal Structures of Clay Minerals" G. Brown, Ed. (Mineralogical Society, London, 1961).

47. G. BROWN and G. W. BRINDLEY, in "Crystal Structures of Clay Minerals and Their X-Ray Identification" G. W. Brindley, G. Brown, Eds. (Mineralogical Society, London, 1980) pp. 305.

48. W. F. BRADLEY and R. E. GRIM, in "The X-Ray Identification and Crystal Structures of Clay Minerals" G. Brown, Ed. (Mineralogical Society, London, 1961).

49. NANOCOR, http://www.nanocor.com/ (2002).

50. T. B. TOLLE and D. P. ANDERSON, Composites Sci. Tech. 62, 1033 (2002).

51. B. D. CULLITY, "Elements of X-Ray Diffraction" (Addison-Wesley Publishing Company, Reading, MA, USA, ed. Second, 1978).

52. H. HUANG, G. L. WILKES and J. G. CARLSON, Polymer 30, 2001 (1989).

53. P. B. MESSERSMITH and E. P. GIANNELIS, Chem. Mater. 6, 1719 (1994).

54. J. M. BROWN, D. CURLISS and R. A. VAIA, Chem. Mater. 12, 3376 (2000).

55. D. C. LEE and L. W. JANG, J. Appl. Polymer Sci. 61, 1117 (1996).

56. A. ALI, “Final Year Project Report” (Imperial College London, 2002). 
57. D. SHIA, C. Y. HUI, S. D. BURNSIDE and E. P. GIANNELIS, Polymer Composites 19, 608 (1998).

58. T. VANORIO, M. PRASAD and A. NUR, Geophysical J. Int. 155, 319 (2003).

59. O. L. MANEVITCH and G. C. RUTLEDGE, J. Phys. Chem. B 108, 1428 (2004).

60. G. WYPYCH, "Handbook of Fillers" (ChemTec Publishing, Toronto, Canada, ed. 2, 1999).

61. B. B. L. MADHUKAR and S. N. P. SRIVASTAVA, "Mica and Mica Industry" (A.A. Balkema, Rotterdam, 1995).

62. L. E. MCNEIL and M. GRIMSDITCH, J. Phys.-Condes. Matter 5, 1681 (1993).

63. R. E. GRIM, "Applied Clay Mineralogy" (McGraw-Hill, New York, 1962).

64. N. SHENG, M. C. BOYCE, D. M. PARKS, G. C. RUTLEDGE, J. I. ABES and R. E. COHEN, Polymer 45, 487 (2004).

65. K. ARAKAWA and K. TAKAHASHI, Int. J. Frac. 48, 103 (1995).

66. D. HULL, J. Mater. Sci. 31, 4483 (1996).

67. D. HULL, "Fractography: Observing, Measuring, and Interpreting Fracture Surface Topography" (Cambridge University Press, Cambridge, 1999).

68. A. S. ZERDA and A. J. LESSER, J. Polym. Sci. B: Polymer Phys. 39, 1137 (2001).

69. E. E. UNDERWOOD, "Quantitative Stereology" (Addison-Wesley Publishing Company, Reading, USA, 1970).

70. R. BAGHERI and R. A. PEARSON, Polymer 41, 269 (2000).

71. R. J. M. BORGGREVE, R. J. GAYMANS and H. M. EICHENWALD, Polymer 30, 78 (1989).

72. S. WU, Polymer 26, 1855 (1985).

73. B. B. JOHNSEN, A. J. KINLOCH and A. C. TAYLOR, (To be published). 
Table 1: Silicates used in the present work.

\begin{tabular}{|c|c|c|c|c|}
\hline Silicate & Supplier & $\begin{array}{c}\text { Surface } \\
\text { treatment }\end{array}$ & $\begin{array}{c}\text { Particle } \\
\text { diameter }\end{array}$ & $\begin{array}{c}\text { Aspect } \\
\text { ratio }\end{array}$ \\
\hline Mica R120 & Minelco, UK & None & $50 \mu \mathrm{m}$ & 15 \\
\hline Cloisite $\mathrm{Na}^{+}$ & Southern Clay Products, USA & None & $25 \mu \mathrm{m}$ & 4 \\
\hline Cloisite 25A & Southern Clay Products, USA & 2MHTL8 & $10 \mu \mathrm{m}$ & 4 \\
\hline Cloisite 30B & Southern Clay Products, USA & MT2EtOT & $10 \mu \mathrm{m}$ & 4 \\
\hline Nanomer I30E & Nanocor, USA & Octadecylamine & $10 \mu \mathrm{m}$ & 4 \\
\hline
\end{tabular}

Notes:

2MHTL8: Dimethyl, hydrogenated tallow, 2-ethylhexyl quaternary ammonium

MT2EtOT: Methyl, tallow, bis-2-hydroxyethyl, quaternary ammonium

Particle diameter and aspect ratio measured using laser light scattering 
Table 2: Wide-angle (WAXS) and small-angle X-ray scattering (SAXS) data for silicates and silicateepoxy composites.

\begin{tabular}{|c|c|c|c|c|}
\hline \multirow[t]{2}{*}{ Silicate } & \multicolumn{3}{|c|}{ d-spacing, $\AA$} & \multirow[t]{2}{*}{ Morphology } \\
\hline & $\begin{array}{l}\text { Silicate } \\
\text { (WAXS) }\end{array}$ & $\begin{array}{c}\text { 5wt.\% composite } \\
\text { (WAXS) }\end{array}$ & $\begin{array}{c}\text { 5wt.\% composite } \\
\text { (SAXS) }\end{array}$ & \\
\hline Mica & 10.0 & 10.0 & $\mathrm{n} / \mathrm{d}$ & Particulate \\
\hline Cloisite $\mathrm{Na}^{+}$ & 12.2 & 12.5 & $\mathrm{n} / \mathrm{d}$ & Particulate \\
\hline Cloisite 25A & 18.9 & 31.3 & $\mathrm{n} / \mathrm{d}$ & Intercalated \\
\hline Cloisite 30B & 18.4 & 39.6 & 38.3 & Intercalated \\
\hline Nanomer I30E & 25.4 & $>58.9$ & 102 & Ordered exfoliated \\
\hline
\end{tabular}

Note:

$\mathrm{n} / \mathrm{d}$ : Not determined 
Table 3: Glass transition temperatures measured using DSC of epoxy and composites using 5 and 10wt.\% silicate.

\begin{tabular}{|c|c|c|c|c|}
\hline Silicate & \multicolumn{3}{|c|}{$\mathbf{T}_{\mathbf{g}},{ }^{\circ} \mathbf{C}$} & Morphology \\
& 0wt.\% & $5 \mathrm{wt} . \%$ & $10 \mathrm{wt} . \%$ & \\
\hline Mica & 67 & 67 & 69 & Particulate \\
\hline Cloisite $\mathrm{Na}^{+}$ & 67 & 67 & 68 & Particulate \\
\hline Cloisite 25A & 67 & 69 & 71 & Intercalated \\
\hline Cloisite 30B & 67 & 71 & 72 & Intercalated \\
\hline Nanomer I30E & 67 & 72 & 76 & Ordered exfoliated \\
\hline
\end{tabular}


Table 4: Values used for theoretical prediction of tensile modulus.

\begin{tabular}{|c|c|c|c|c|c|c|c|}
\hline Variable & Source & $\begin{array}{l}\text { Symbol } \\
\text { \& Units }\end{array}$ & Mica & $\begin{array}{c}\text { Cloisite } \\
\mathrm{Na}^{+}\end{array}$ & $\begin{array}{c}\text { Cloisite } \\
\text { 30B }\end{array}$ & $\begin{array}{c}\text { Cloisite } \\
25 \mathrm{~A}\end{array}$ & $\begin{array}{c}\text { Nanomer } \\
\text { I30E }\end{array}$ \\
\hline $\begin{array}{l}\text { Tensile modulus of } \\
\text { epoxy }\end{array}$ & (a) & $\begin{array}{l}\mathrm{E}_{\mathrm{m}}, \\
\mathrm{GPa}\end{array}$ & \multicolumn{5}{|c|}{3.05} \\
\hline $\begin{array}{l}\text { Poisson's ratio of } \\
\text { epoxy }\end{array}$ & {$[43]$} & $v_{m}$ & \multicolumn{5}{|c|}{0.35} \\
\hline $\begin{array}{l}\text { Shear modulus of } \\
\text { epoxy }\end{array}$ & (a) & $\begin{array}{l}\mathrm{G}_{\mathrm{m}} \\
\mathrm{GPa}\end{array}$ & \multicolumn{5}{|c|}{1.13} \\
\hline $\begin{array}{l}\text { Tensile modulus of } \\
\text { particles }\end{array}$ & $\begin{array}{l}60, \\
62]\end{array}$ & $\mathrm{E}_{\mathrm{f}}, \mathrm{GPa}$ & 172 & 172 & $44.8^{(\mathrm{b})}$ & $40.9^{(\mathrm{b})}$ & $23.0^{(\mathrm{b})}$ \\
\hline $\begin{array}{l}\text { Silicate volume } \\
\text { fraction of particles }\end{array}$ & $\begin{array}{l}{[30,} \\
31,49]\end{array}$ & - & 1 & 1 & 0.70 & 0.66 & 0.66 \\
\hline $\begin{array}{l}\text { Aspect ratio of } \\
\text { particles }\end{array}$ & (a) & $\mathrm{w} / \mathrm{t}$ & 15 & 4 & $2^{\text {(d) }}$ & $2^{\text {(d) }}$ & $1^{\text {(d) }}$ \\
\hline Orientation correction & [35] & $\mu_{\mathrm{o}}$ & \multicolumn{5}{|c|}{0.2} \\
\hline
\end{tabular}

Notes:
a. Measured or calculated from experimental data
b. Calculated using equation 1 , with $\mathrm{E}_{\mathrm{f}}=172 \mathrm{GPa}, \mathrm{E}_{\mathrm{m}}=3.05 \mathrm{GPa}$
c. Organoclays contain $70 \%$ silicate and $30 \%$ surfactant or $66 \%$ silicate and $34 \%$ surfactant.
d. After intercalation 
Table 5: Values of particle volume fraction and mean free distance calculated for composition with maximum measured fracture energy.

\begin{tabular}{|lc|c|c|}
\hline \multirow{2}{*}{ Silicate } & Source & $\begin{array}{c}\text { Value at Maximum Fracture Energy } \\
\text { Particle Volume } \\
\text { Fraction, vol.\% }\end{array}$ & $\begin{array}{c}\text { Mean Free Distance, } \\
\mu \mathrm{m}\end{array}$ \\
\hline Mica & $\mathrm{a}$ & 3.6 & 160 \\
\hline Mica & {$[42]$} & 4.5 & 120 \\
\hline Cloisite Na+ & $\mathrm{a}$ & 2.2 & 380 \\
\hline Cloisite 25A & $\mathrm{a}$ & 3.1 & 140 \\
\hline Cloisite 30B & $\mathrm{a}$ & 1.3 & 380 \\
\hline Nanomer I30E & $\mathrm{a}$ & $\leq 2.5$ & $\geq 250$ \\
\hline Nanomer I30E & {$[10]$} & $\leq 4.8$ & 240 \\
\hline Nanomer I28E & {$[68]$} & 2.7 & 240 \\
\hline
\end{tabular}

Note:

a. Measured or calculated from experimental data 


\section{Figure Captions}

Figure 1: Microstructures of epoxy-silicate (clay) composites.

Figure 2: Particle size distribution, $\mathrm{D}(4,3)$, measured by laser light scattering, for mica, Cloisite $\mathrm{Na}^{+}$and Cloisite 25A, prior to incorporation into the epoxy matrix .

Figure 3: Scanning electron micrographs of silicates used, a: mica, b: Cloisite $\mathrm{Na}^{+}$, c: Cloisite 25A.

Figure 4: Wide-angle X-ray scattering data for unmodified epoxy, mica and mica/epoxy microcomposite indicating the presence of a particulate morphology.

Figure 5: Wide-angle X-ray scattering data for unmodified epoxy, Nanomer I30E and I30E/epoxy nanocomposite indicating the presence of an exfoliated morphology.

Figure 6: Wide-angle X-ray scattering data for unmodified epoxy, Cloisite 25A and 25A/epoxy nanocomposite indicating the presence of an intercalated morphology.

Figure 7: Wide-angle X-ray scattering data for unmodified epoxy, Cloisite 30B and 30B/epoxy nanocomposite indicating the presence of an intercalated morphology.

Figure 8: Small-angle X-ray scattering data for epoxy nano-composites with 5wt.\% Cloisite 30B and 5 wt.\% Nanomer I30E.

Figure 9: WAXS texture analysis data for epoxy micro-composite with 20wt.\% mica, at the surface of the plate.

Figure 10: WAXS texture analysis data for epoxy micro-composite with 20wt.\% mica: a: at the surface of the plate, b: at $1 \mathrm{~mm}$ depth, c: at $2 \mathrm{~mm}$ depth, d: at $2.5 \mathrm{~mm}$ depth, showing orientation of platelets at the surface of the plate and less orientation within the plate. (Contours shown at relative intensities of 1 to 2, with increments of 0.25.)

Figure 11: Transmission electron micrograph of epoxy nano-composite with 5wt.\% Cloisite 25A.

Figure 12: Transmission electron micrograph of epoxy nano-composite with 5wt.\% Nanomer I30E.

Figure 13: Tensile modulus of unmodified epoxy, micro- and nano-composites.

Figure 14: Fracture toughness of unmodified epoxy, micro- and nano-composites. 
Figure 15: Tensile modulus versus fracture toughness of unmodified epoxy, micro- and nanocomposites, a: experimental data, b: property map.

Figure 16: Relative modulus (composite modulus divided by unmodified epoxy modulus) versus volume percentage of silicate for particulate composites, a: mica, and b: Cloisite $\mathrm{Na}^{+}$. Points are experimental data and lines are theoretical predictions.

Figure 17: Relative modulus (composite modulus divided by unmodified epoxy modulus) versus volume percentage of silicate for clay-modified epoxy, a: intercalated nano-composites, and b: exfoliated nano-composites. Points are experimental data and lines are theoretical predictions.

Figure 18: Relative fracture energy (composite fracture energy divided by epoxy-matrix fracture energy) versus volume percentage of silicate for micro- and nano-composites. Points are experimental data and bold lines are theoretical predictions using aspect ratios of twelve and three. $\left(G_{m}=275 \mathrm{~J} / \mathrm{m}^{2}\right.$.)

Figure 19: Scanning electron micrographs of fracture surfaces, a: unmodified epoxy, b: 10wt.\% mica, c: 10 wt.\% Cloisite $\mathrm{Na}^{+}$, d: 10 wt.\% Cloisite 30B. (Arrows indicate cavities around particles).

Figure 20: Scanning electron micrographs of fracture surfaces for composites with Cloisite $\mathrm{Na}^{+}$, a: 5wt.\% Cloisite $\mathrm{Na}^{+}$, b: 8wt.\% Cloisite $\mathrm{Na}^{+}$, c: 10 wt. $\%$ Cloisite $\mathrm{Na}^{+}$, d: 15 wt.\% Cloisite $\mathrm{Na}^{+}$, e: $20 \mathrm{wt} . \%$ Cloisite $\mathrm{Na}^{+}$, f: 25wt.\% Cloisite $\mathrm{Na}^{+}$.

Figure 21: Average roughness of fracture surfaces versus a: micro-composite fracture energy, b: nanocomposite fracture energy, c: silicate content for all nano- and micro-composites. (Error bars indicate 1 standard deviation).

Figure 22: Effect of interparticle distance between particles for micro- and nano-composites, a: fracture energy versus mean free distance, b: fracture toughness versus mean free distance. (Solid line is equivalence of plastic zone size in plane stress with mean free distance.) 

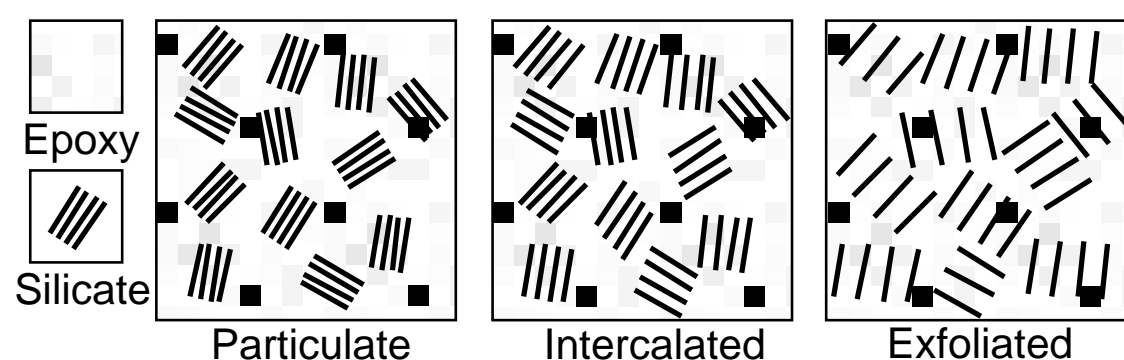

Exfoliated

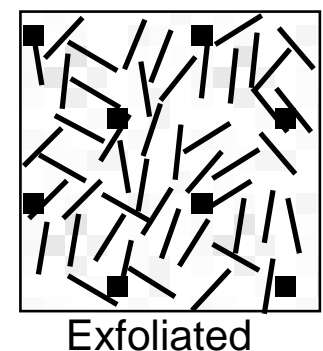

(disordered)

Figure 1: Microstructures of epoxy-silicate (clay) composites. 


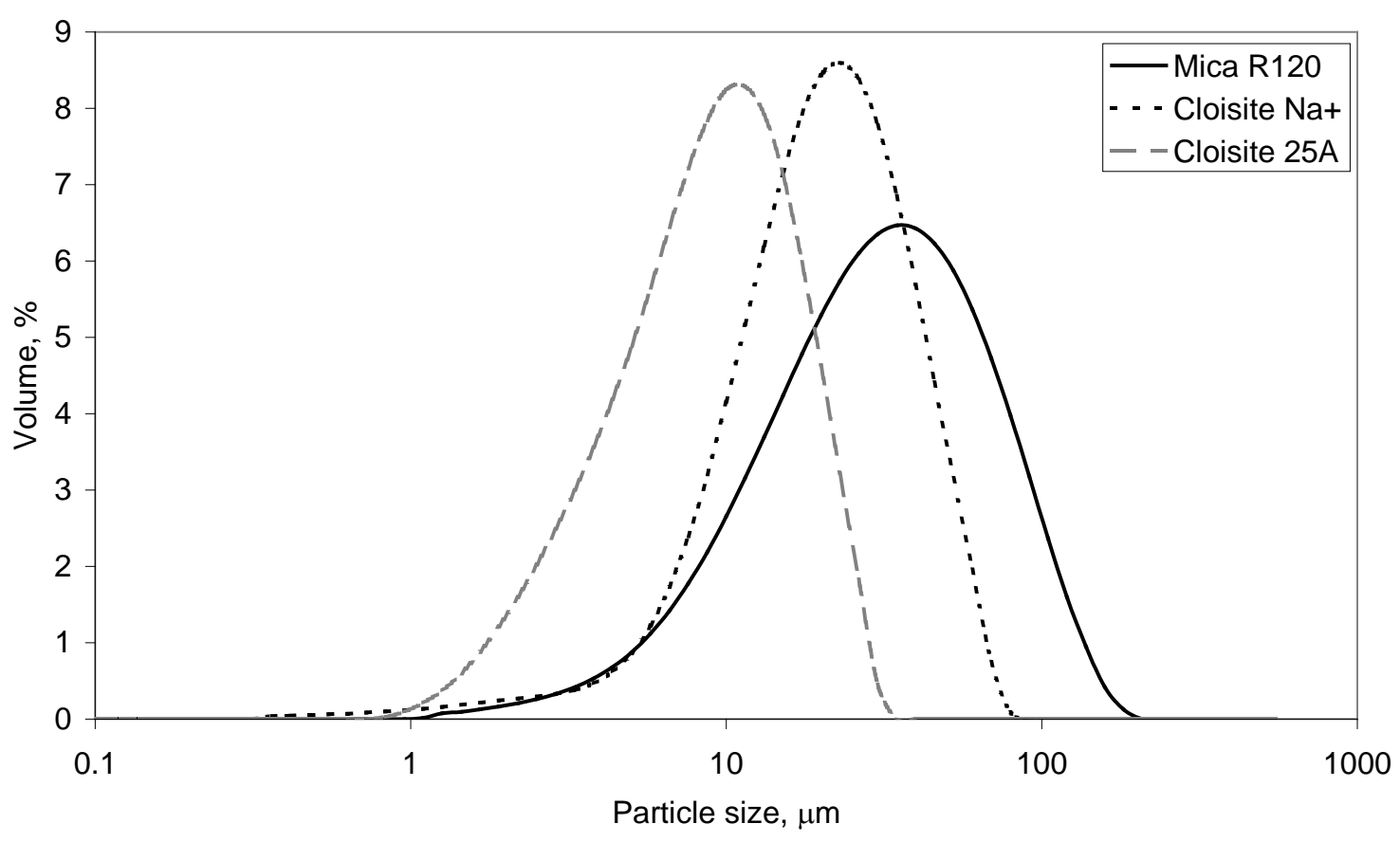

Figure 2: Particle size distribution, D(4,3), measured by laser light scattering, for mica, Cloisite $\mathrm{Na}^{+}$and Cloisite 25A, prior to incorporation into the epoxy matrix . 


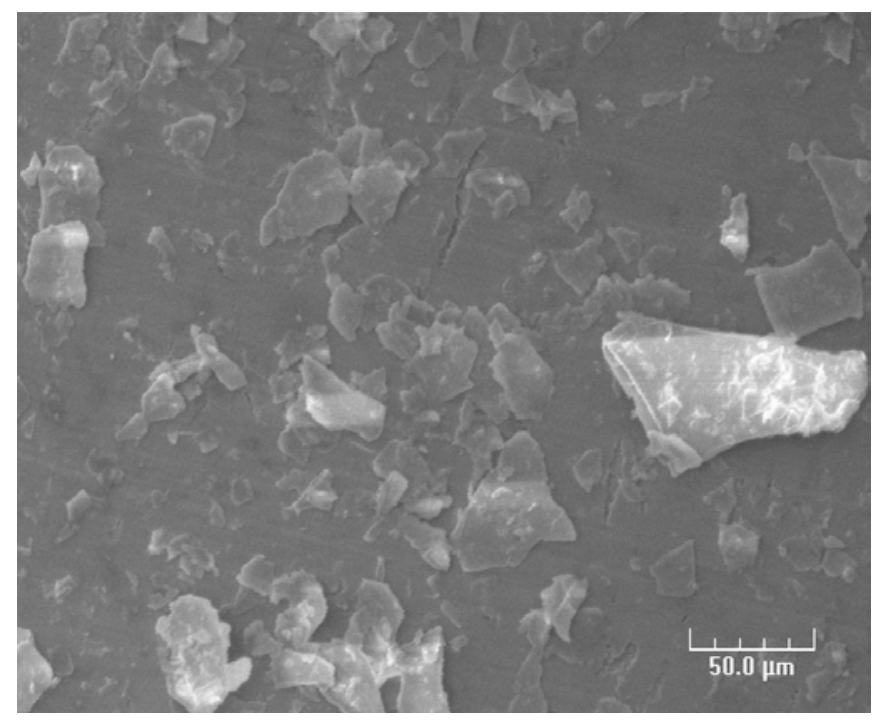

a) Mica.

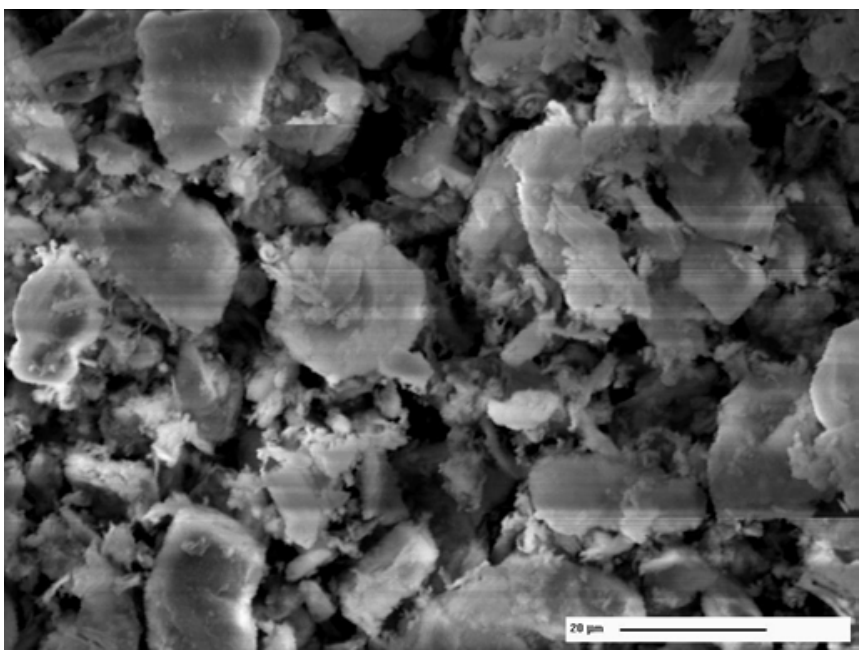

b) Cloisite $\mathrm{Na}^{+}$.

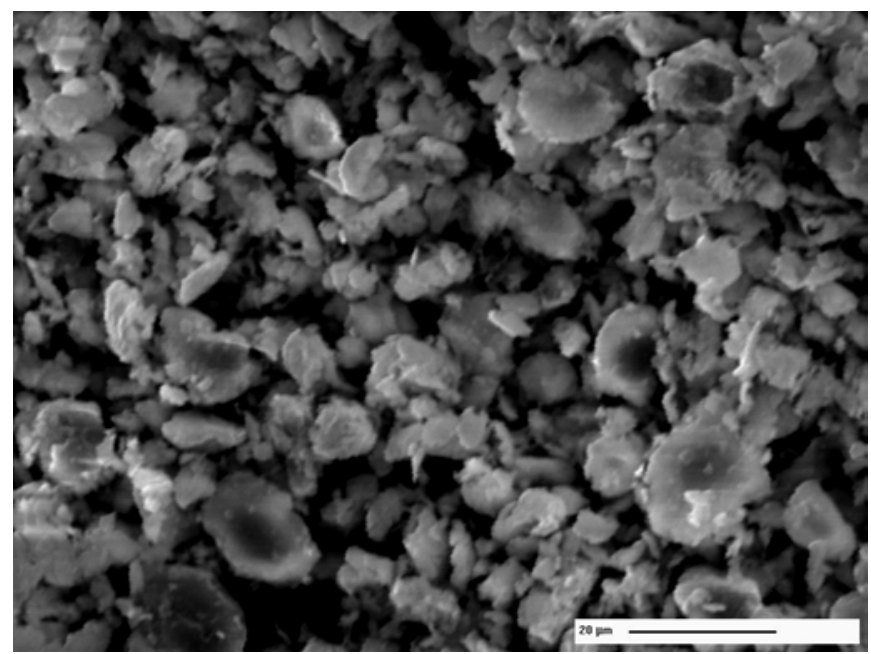

c) Cloisite 25A.

Figure 3: Scanning electron micrographs of silicates used, a: mica, b: Cloisite $\mathrm{Na}^{+}$, c: Cloisite 25A. 


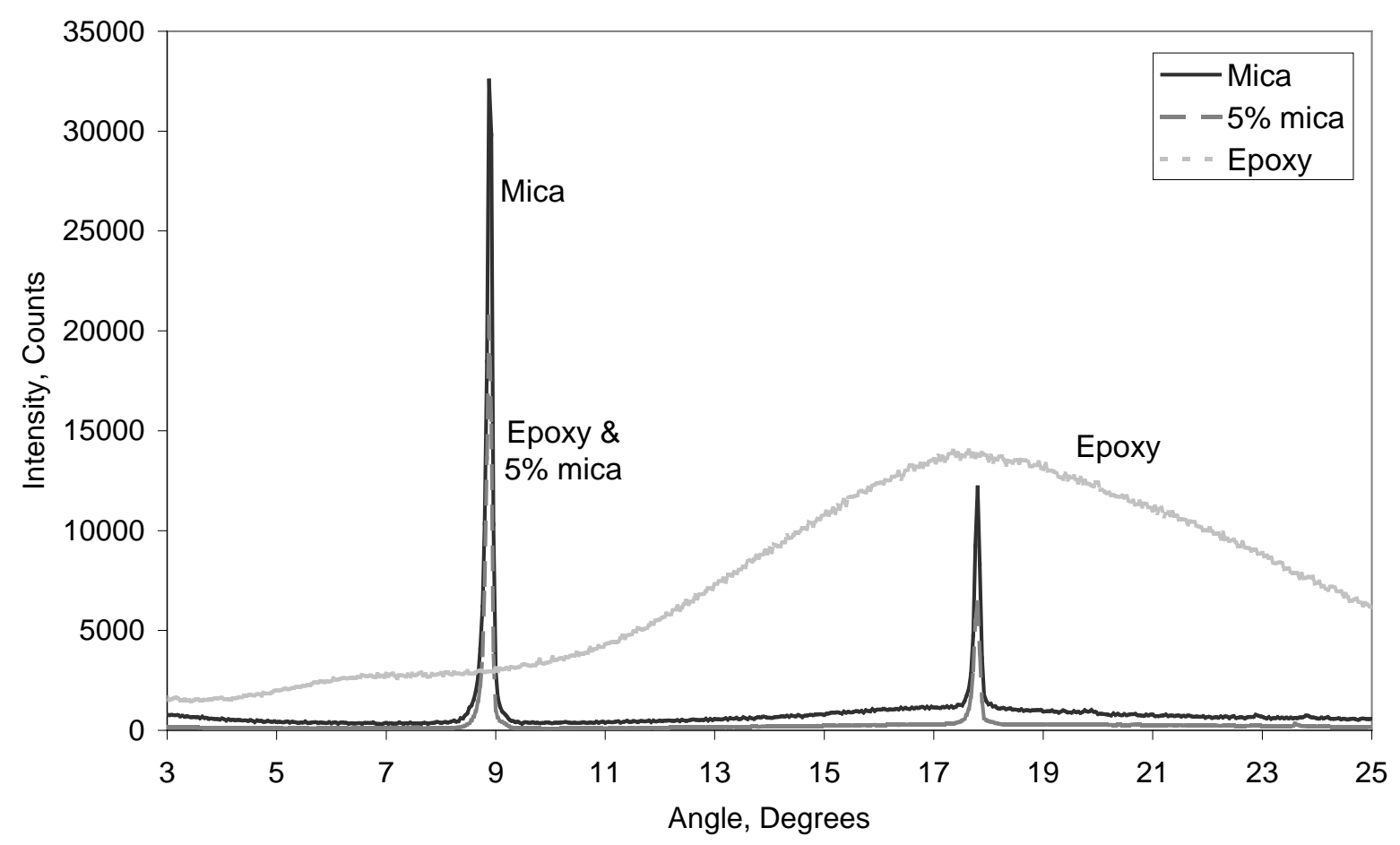

Figure 4: Wide-angle X-ray scattering data for unmodified epoxy, mica and mica/epoxy microcomposite indicating the presence of a particulate morphology. 


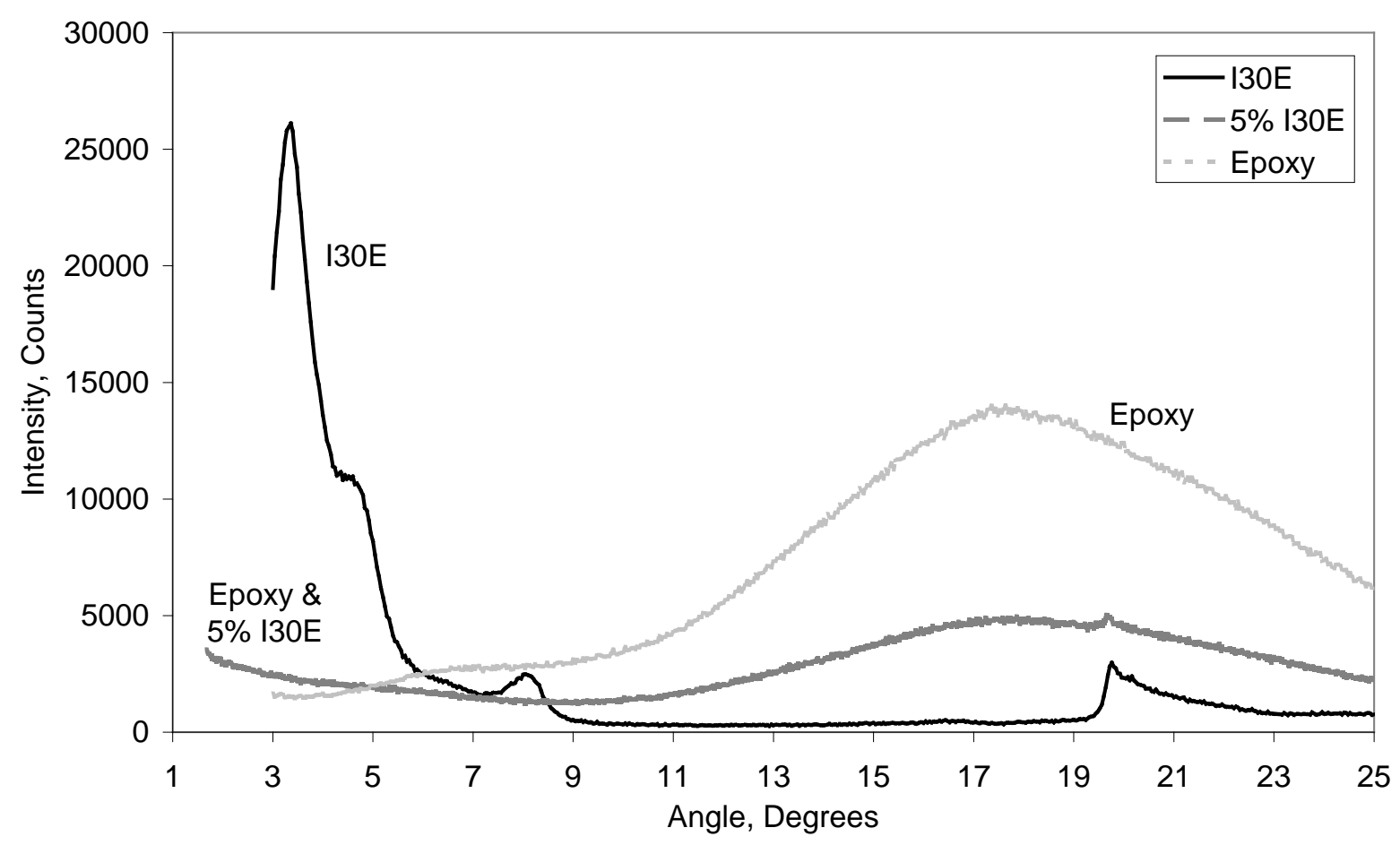

Figure 5: Wide-angle X-ray scattering data for unmodified epoxy, Nanomer I30E and I30E/epoxy nanocomposite indicating the presence of an exfoliated morphology. 


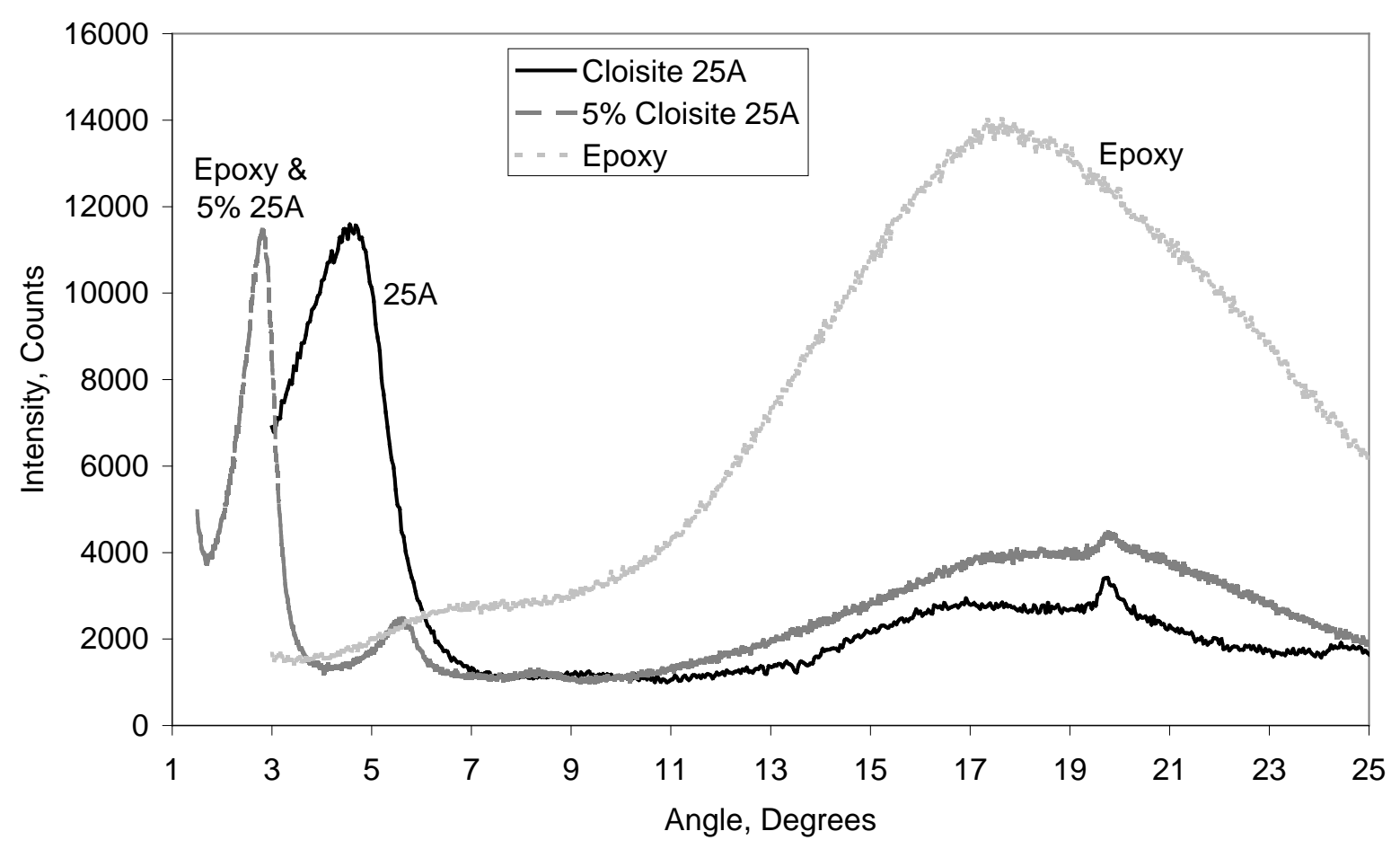

Figure 6: Wide-angle X-ray scattering data for unmodified epoxy, Cloisite 25A and 25A/epoxy nanocomposite indicating the presence of an intercalated morphology. 


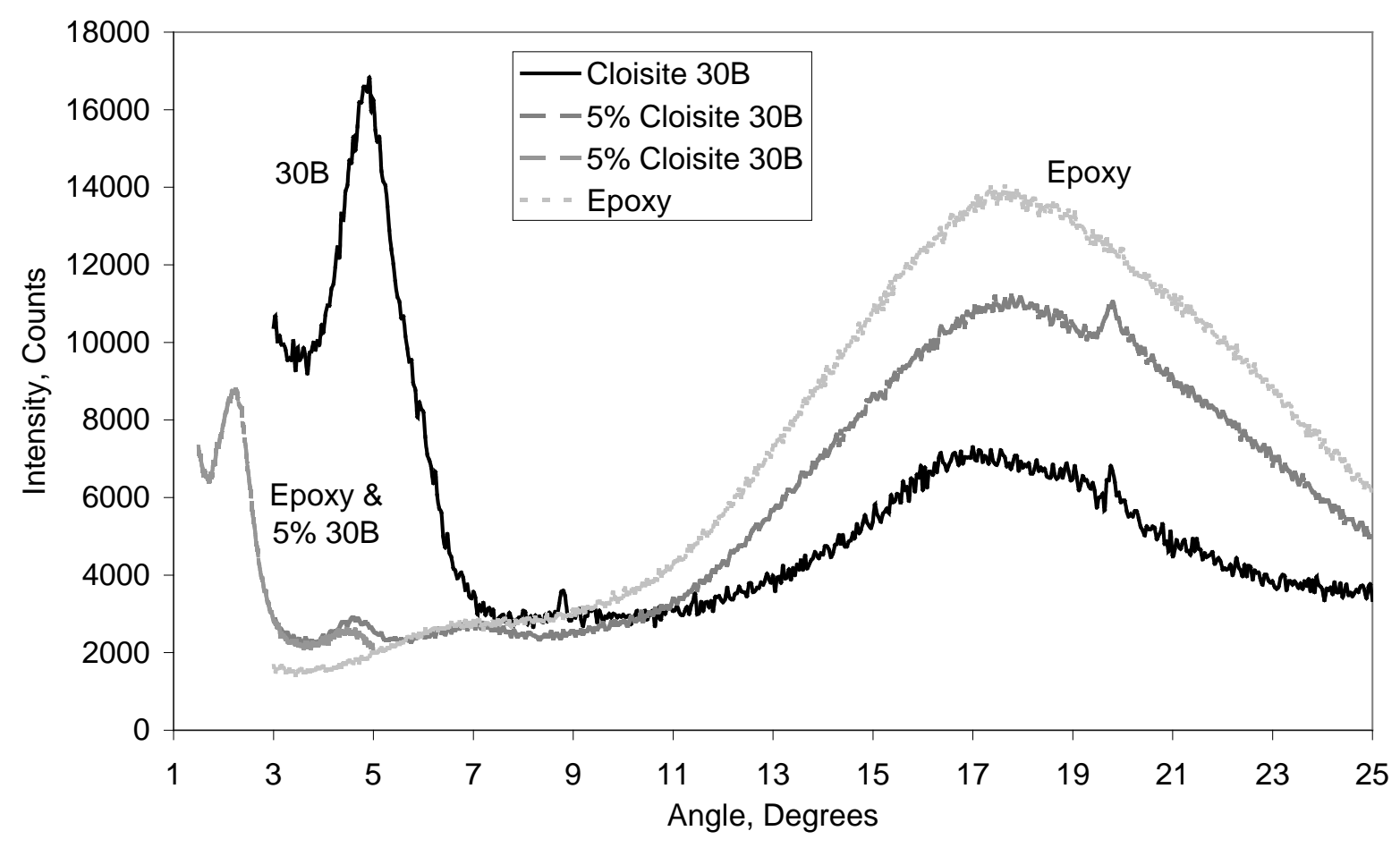

Figure 7: Wide-angle X-ray scattering data for unmodified epoxy, Cloisite 30B and 30B/epoxy nanocomposite indicating the presence of an intercalated morphology. 


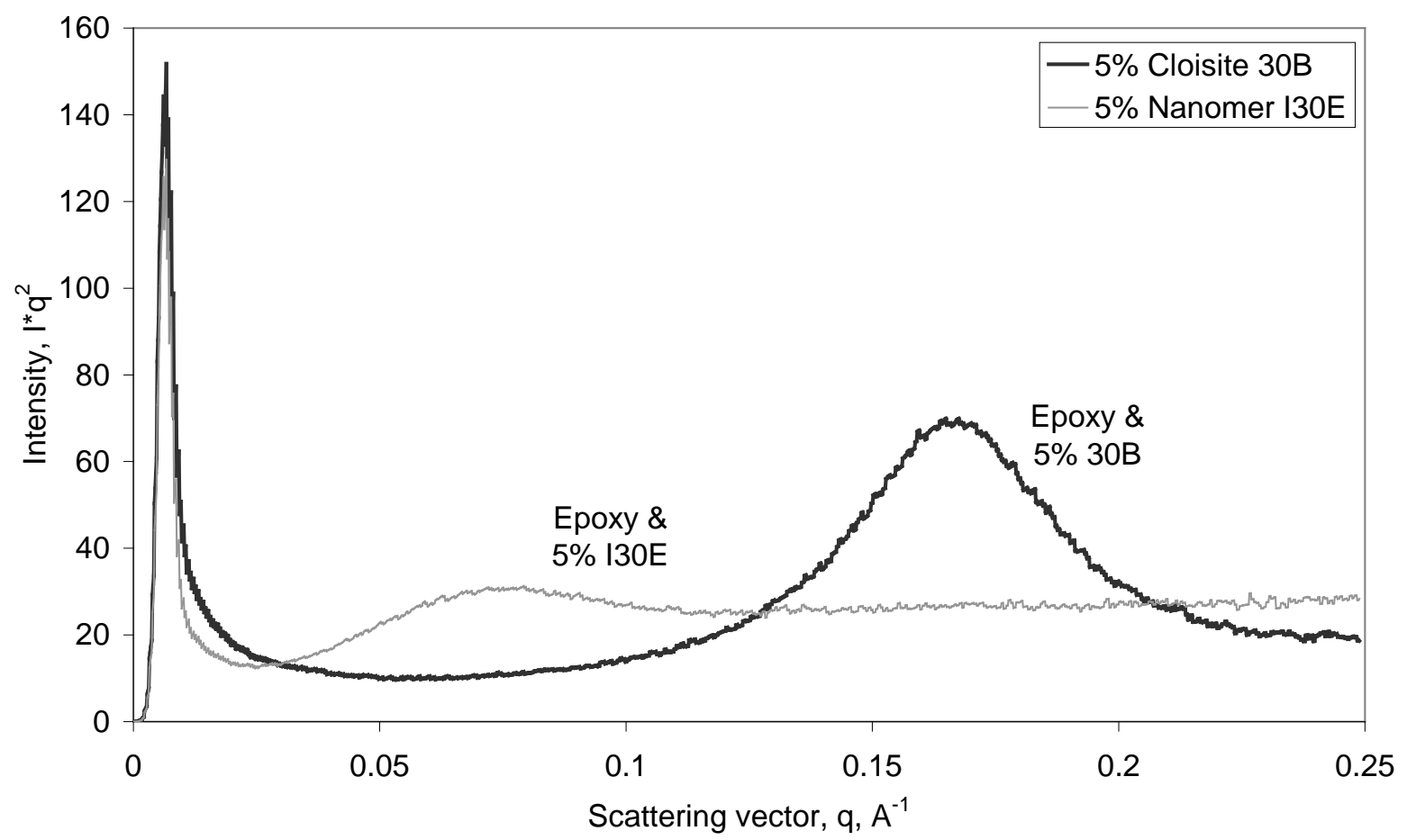

Figure 8: Small-angle X-ray scattering data for epoxy nano-composites with 5wt.\% Cloisite 30B and 5wt.\% Nanomer I30E. 


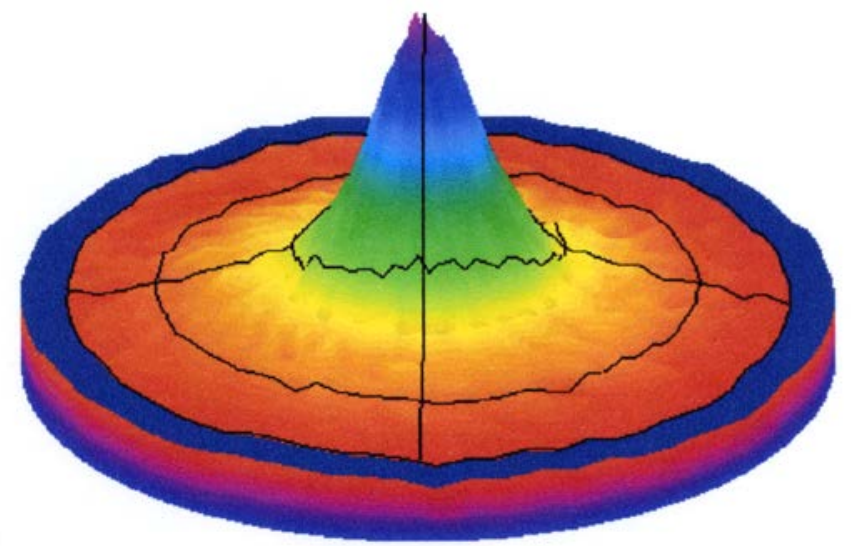

\begin{tabular}{|l|r|r|}
\hline & Intensity & Colour \\
\hline 1 & 857.107 & \\
\hline 2 & 1273.213 & \\
\hline 3 & 1689.320 & \\
\hline 4 & 2105.427 & \\
\hline 5 & 2521.533 & \\
\hline
\end{tabular}

Figure 9: WAXS texture analysis data for epoxy micro-composite with 20wt.\% mica, at the surface of the plate. 


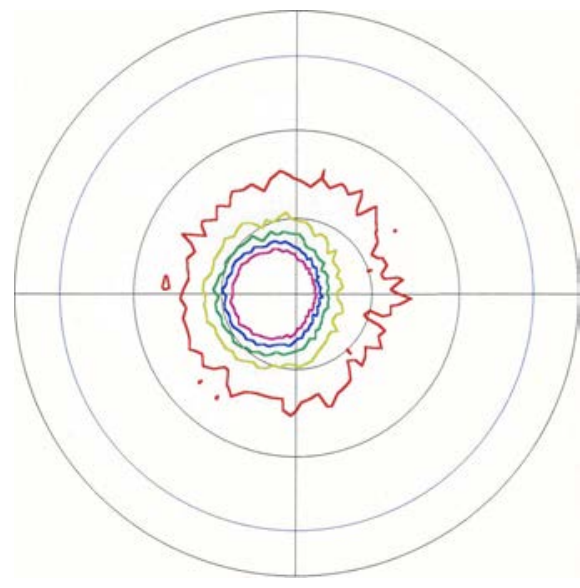

a) At the surface

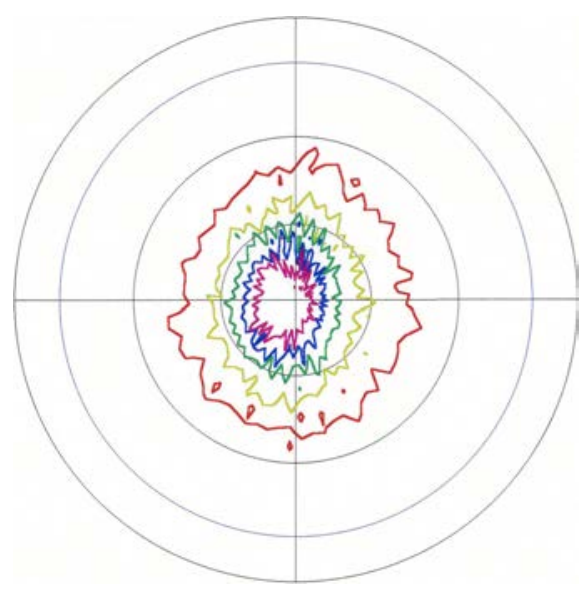

c) At $2 \mathrm{~mm}$ depth.

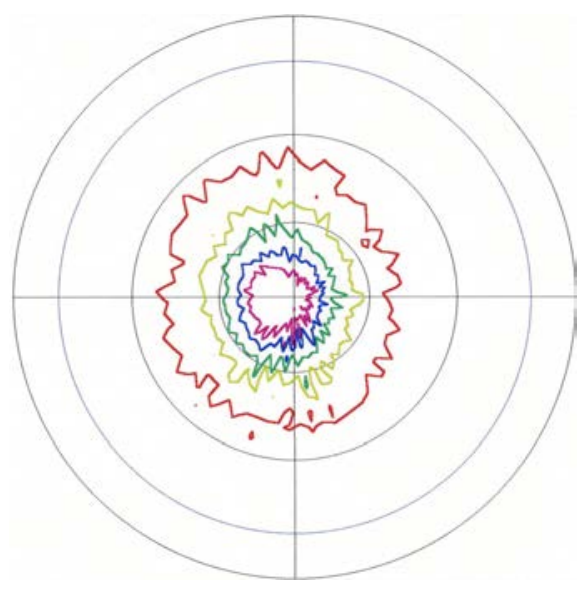

b) At $1 \mathrm{~mm}$ depth

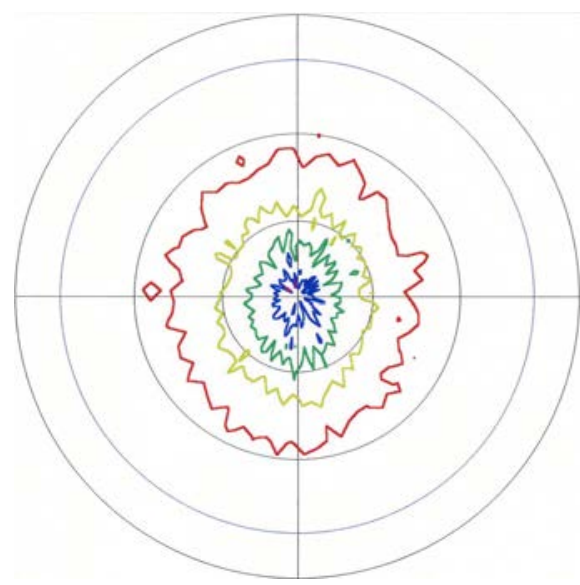

d) At $2.5 \mathrm{~mm}$ depth.

\begin{tabular}{|l|r|r|}
\hline & Intensity & Colour \\
\hline 1 & 1.000 \\
\hline 2 & 1.250 \\
\hline 3 & 1.500 \\
\hline 4 & 1.750 \\
\hline 5 & 2.000 \\
\hline
\end{tabular}

Figure 10: WAXS texture analysis data for epoxy micro-composite with 20wt.\% mica: a: at the surface of the plate, b: at $1 \mathrm{~mm}$ depth, c: at $2 \mathrm{~mm}$ depth, d: at $2.5 \mathrm{~mm}$ depth, showing orientation of platelets at the surface of the plate and less orientation within the plate. (Contours shown at relative intensities of 1 to 2, with increments of 0.25 .) 


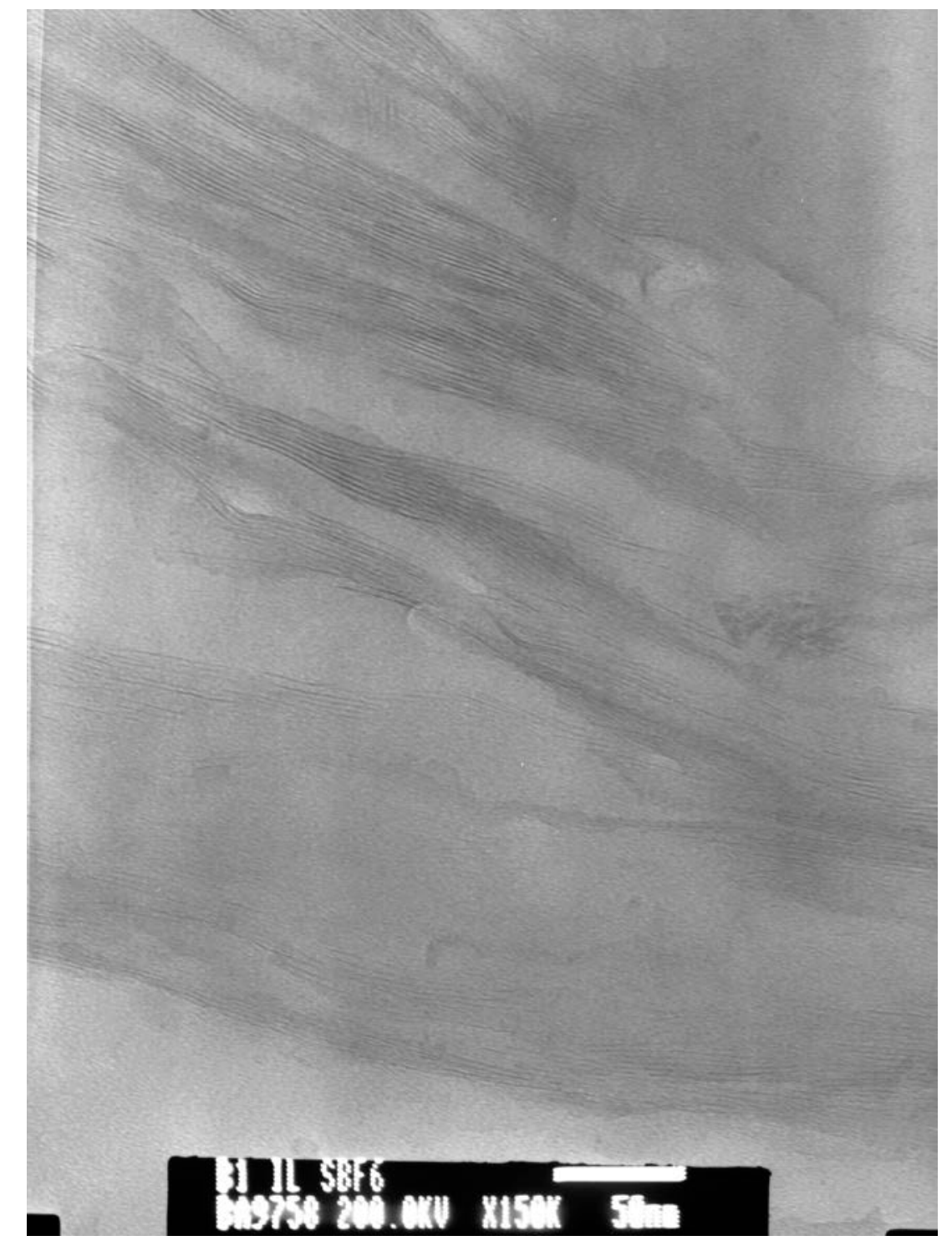

Figure 11: Transmission electron micrograph of epoxy nano-composite with 5wt.\% Cloisite 25A. 


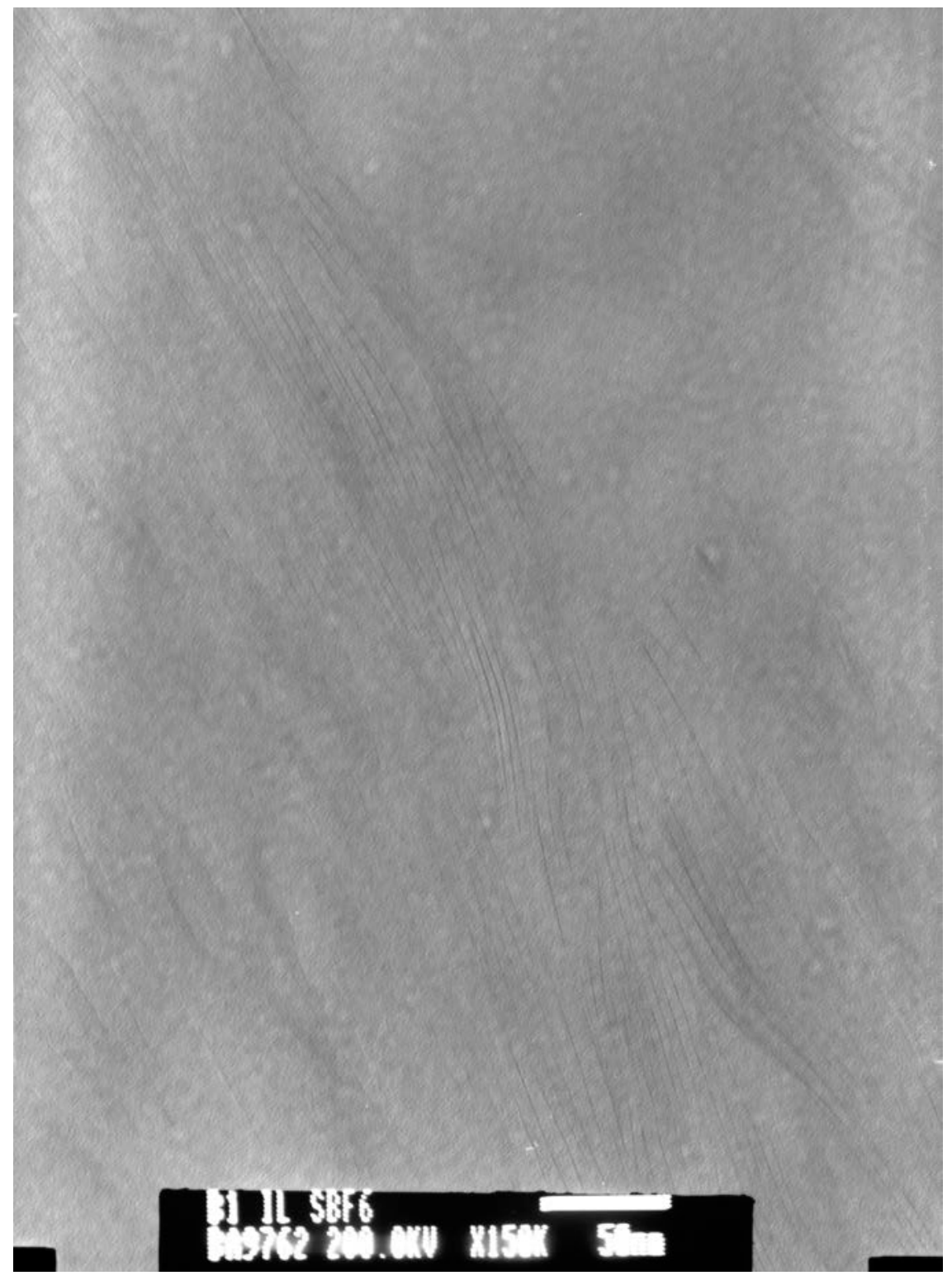

Figure 12: Transmission electron micrograph of epoxy nano-composite with 5wt.\% Nanomer I30E. 


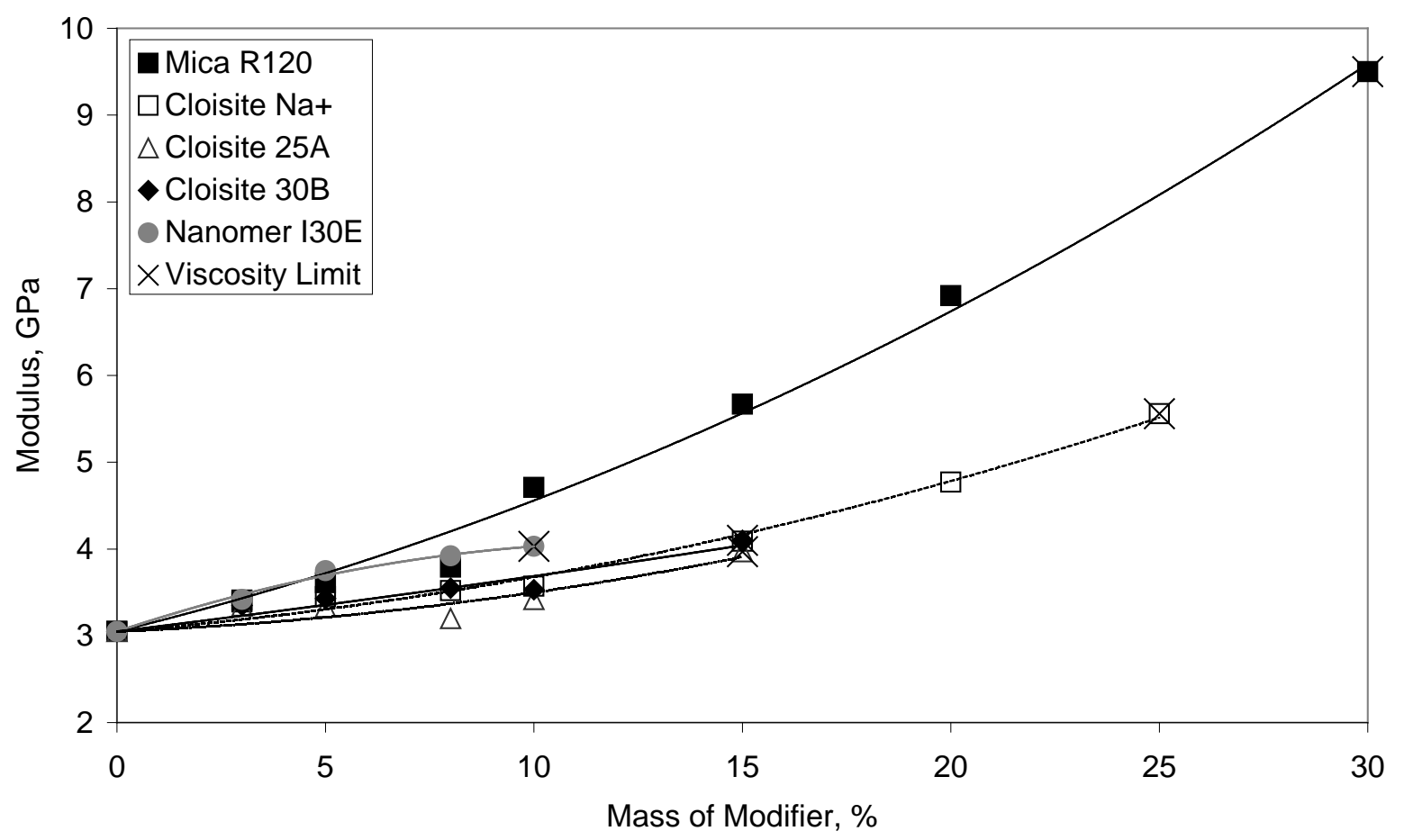

Figure 13: Tensile modulus of unmodified epoxy, micro- and nano-composites. 


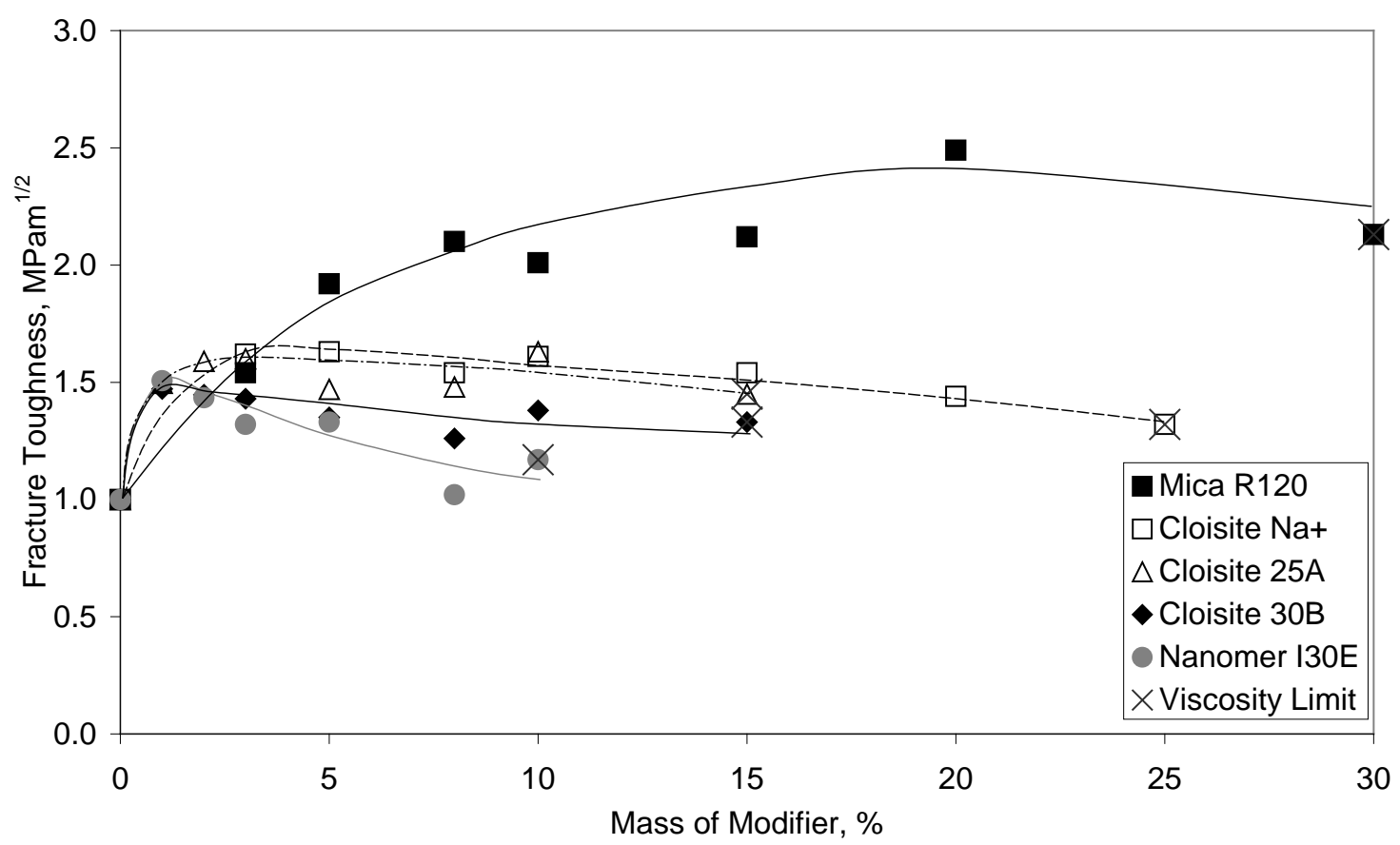

Figure 14: Fracture toughness of unmodified epoxy, micro- and nano-composites. 


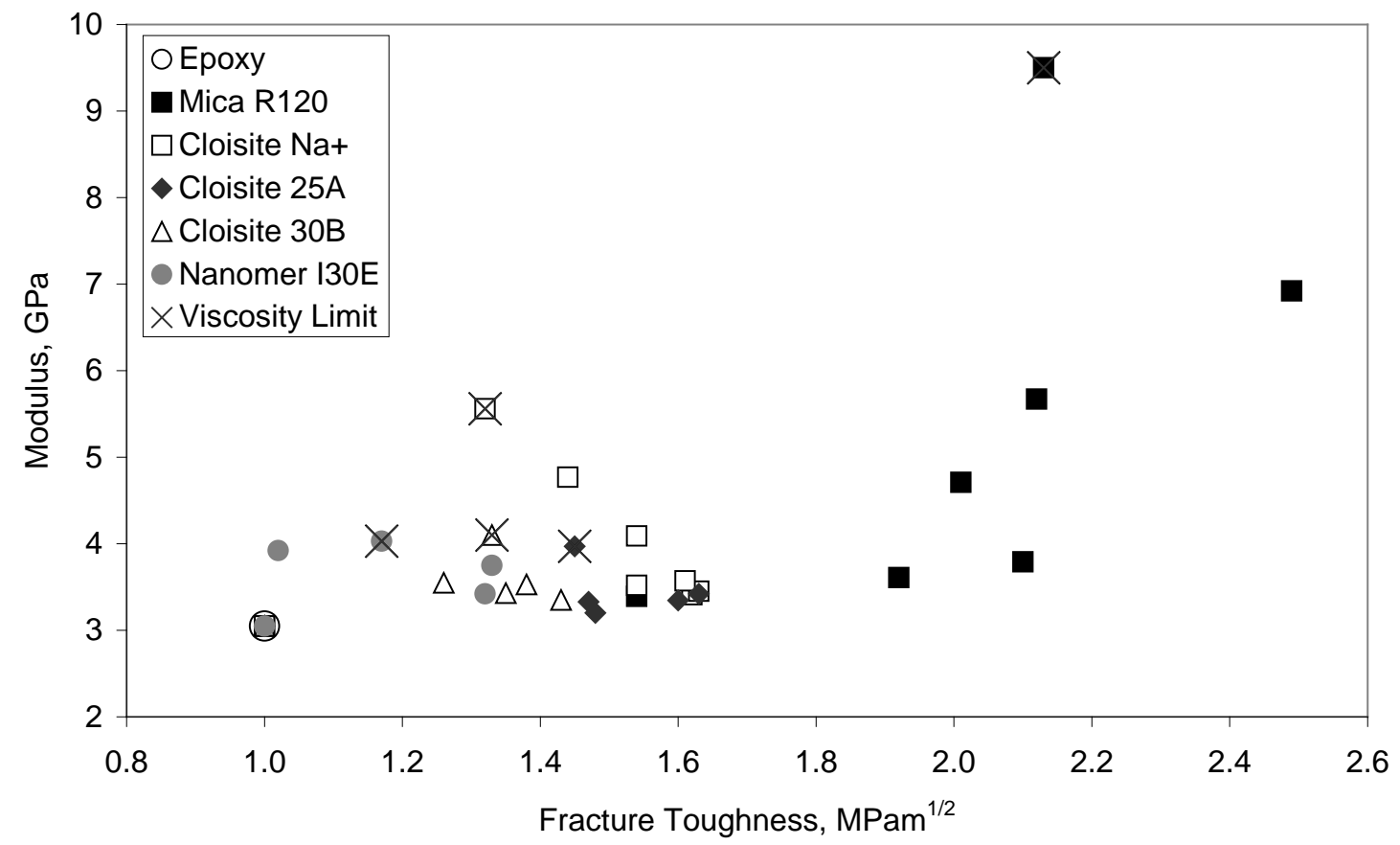

a: Experimental data.

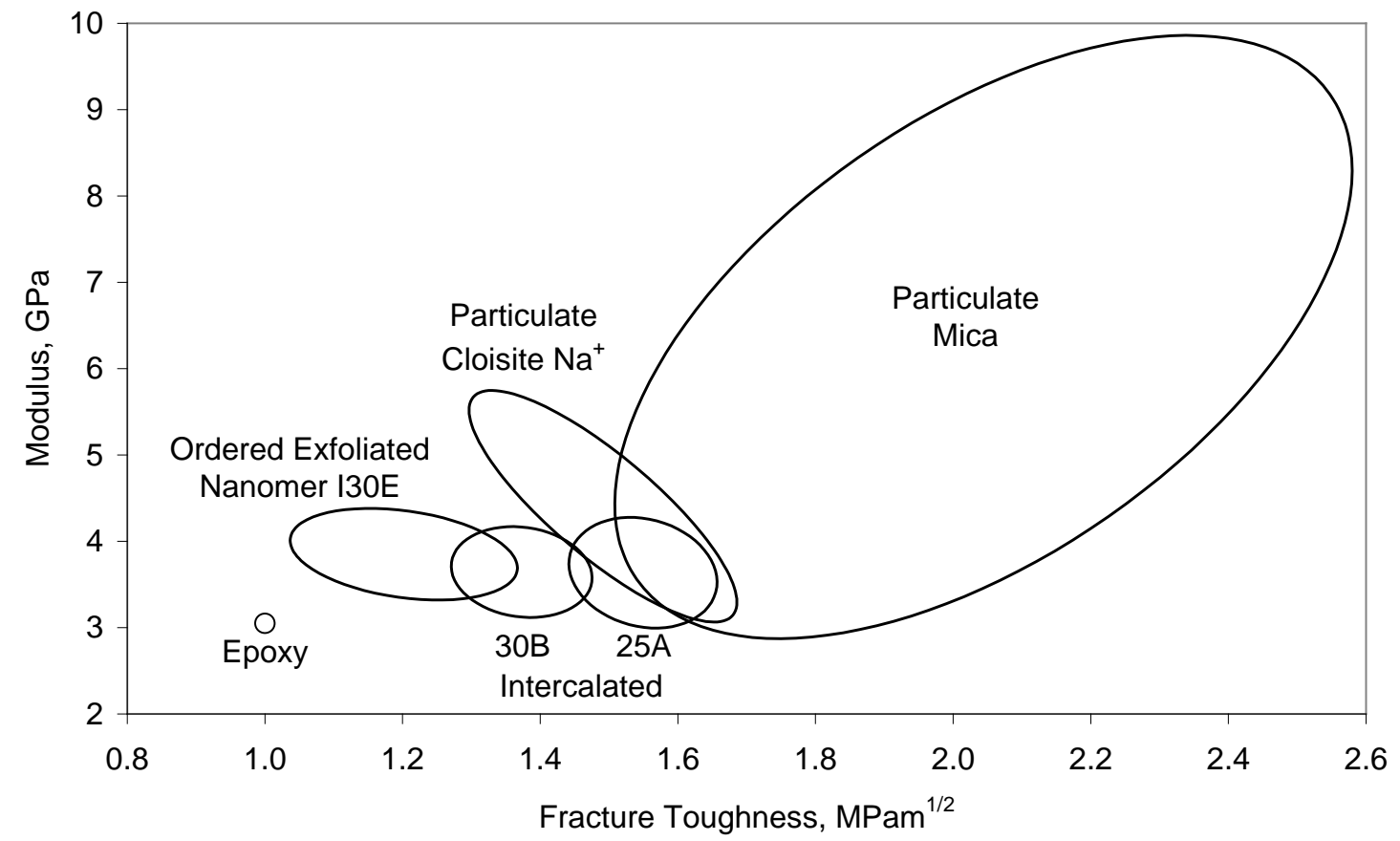

b: Property map

Figure 15: Tensile modulus versus fracture toughness of unmodified epoxy, micro- and nanocomposites, a: experimental data, b: property map. 


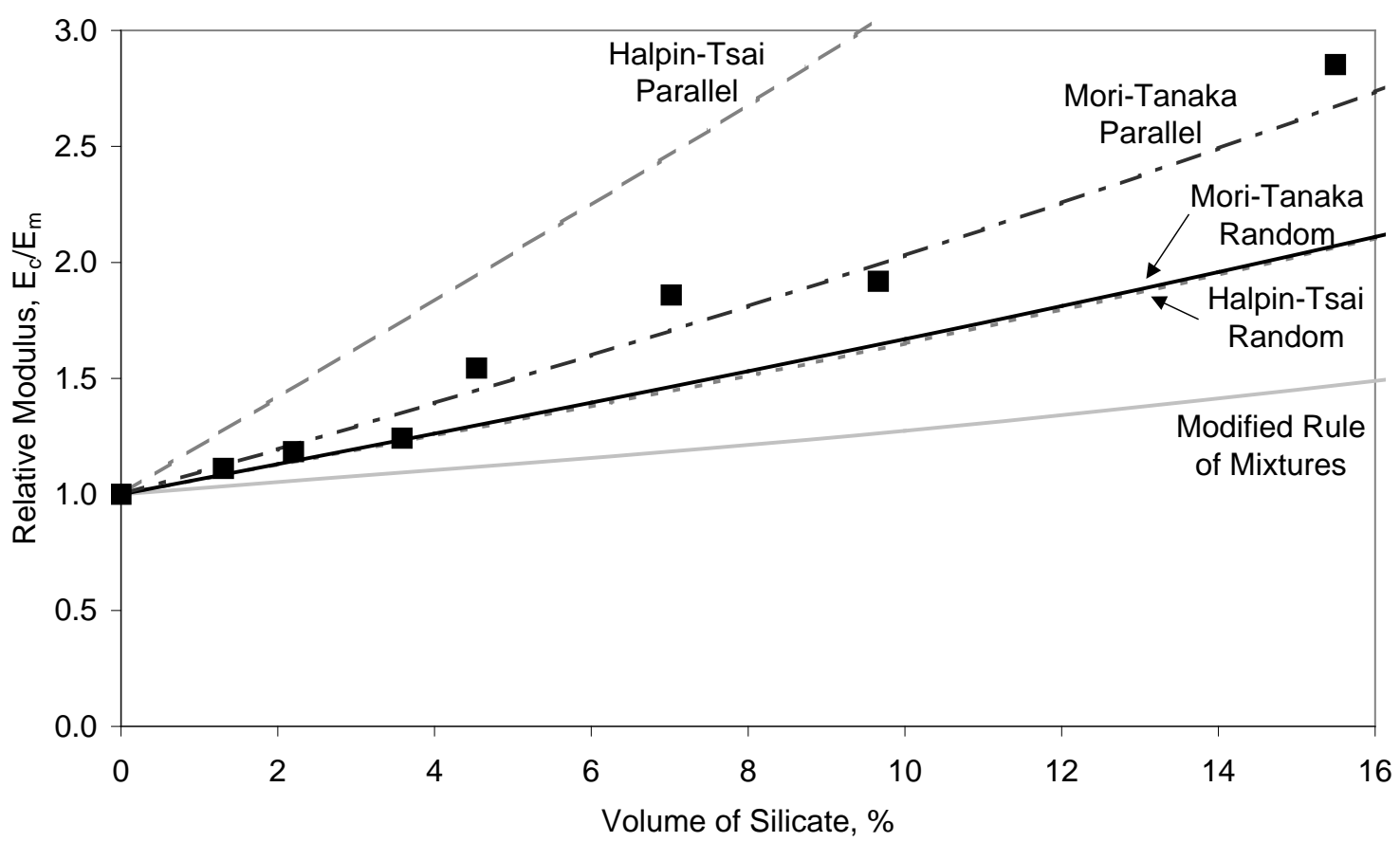

a: Mica

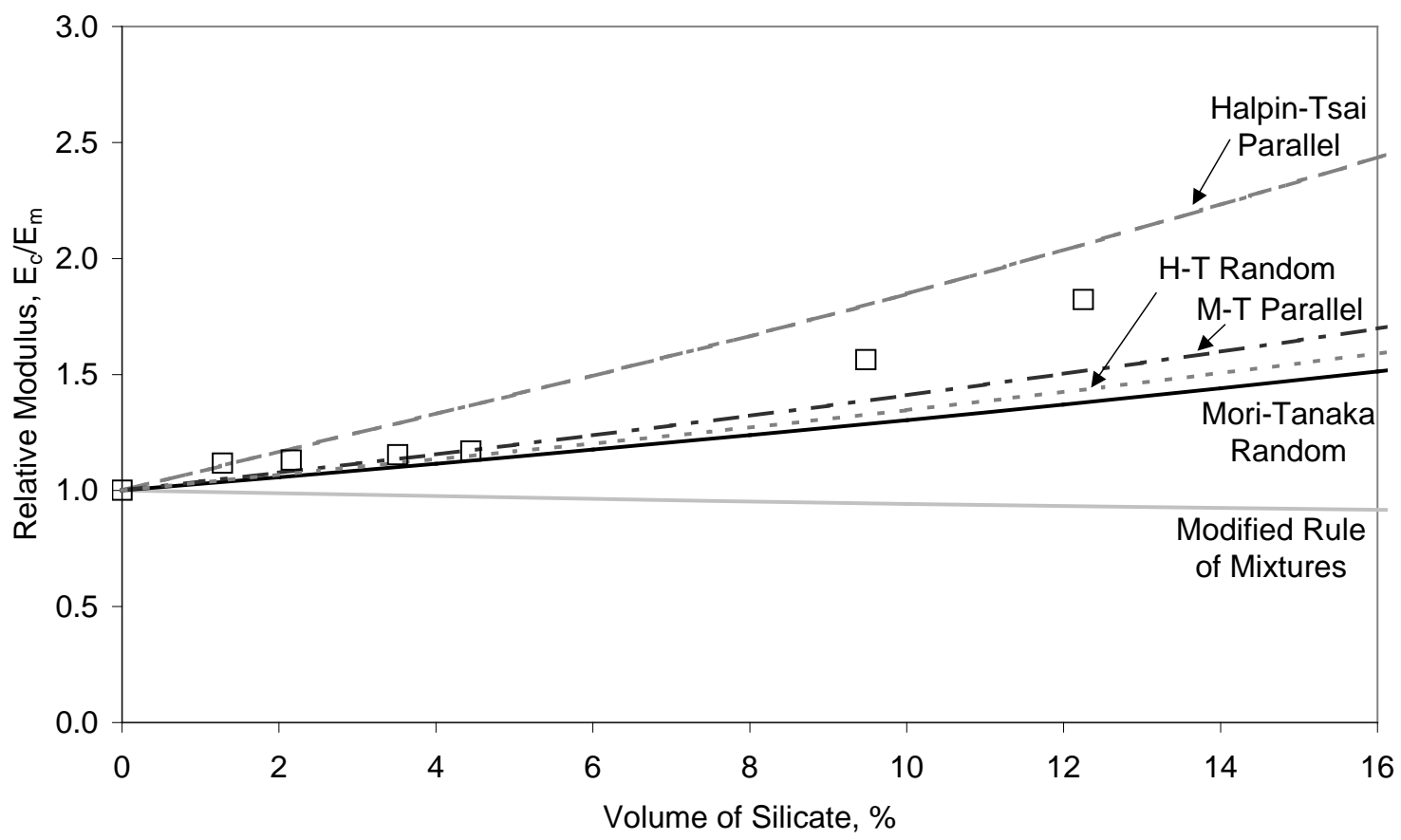

b: Cloisite $\mathrm{Na}^{+}$

Figure 16: Relative modulus (composite modulus divided by unmodified epoxy modulus) versus volume percentage of silicate for particulate composites, a: mica, and b: Cloisite $\mathrm{Na}^{+}$. Points are experimental data and lines are theoretical predictions. 


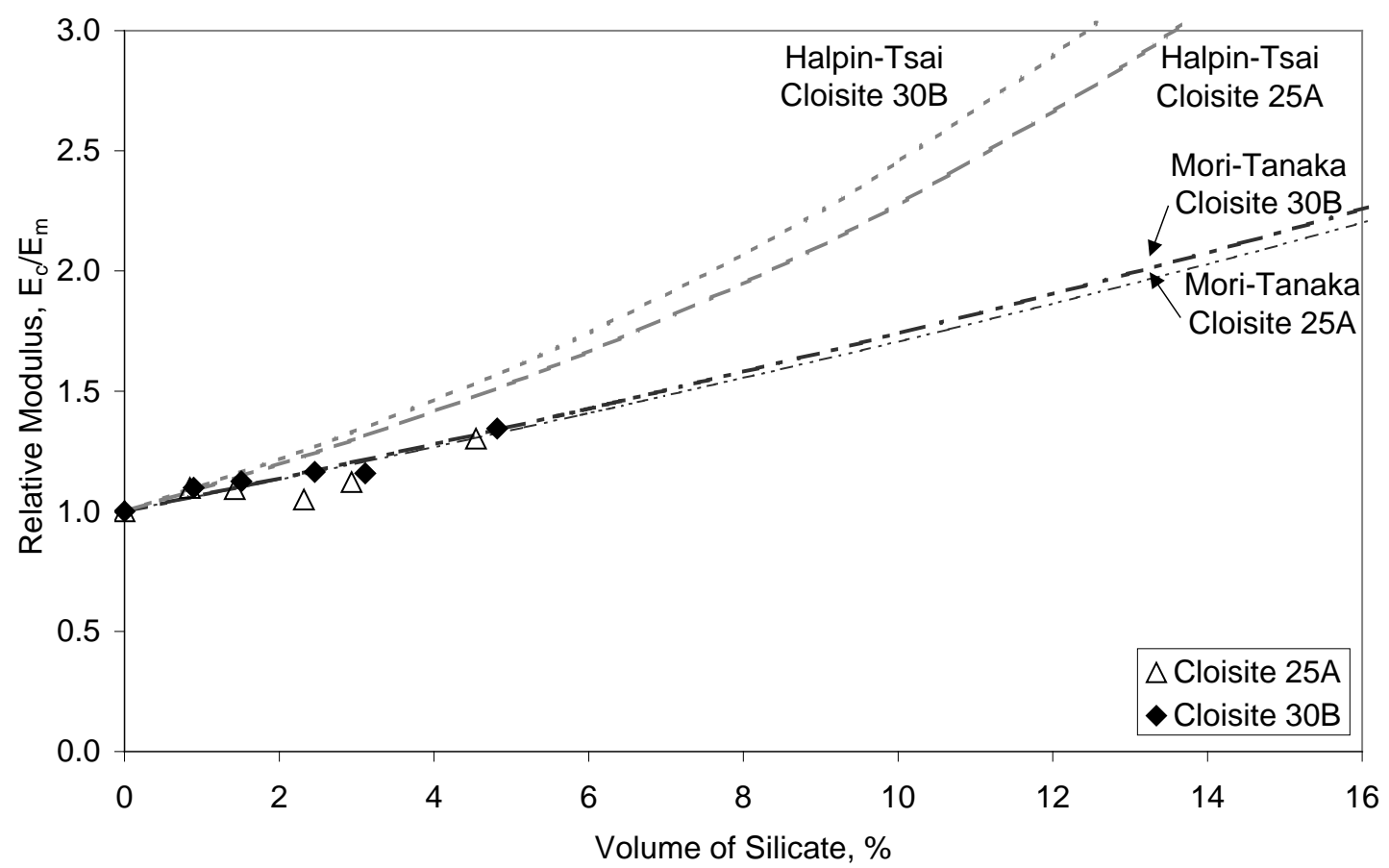

a: Intercalated nano-composites (random models only)

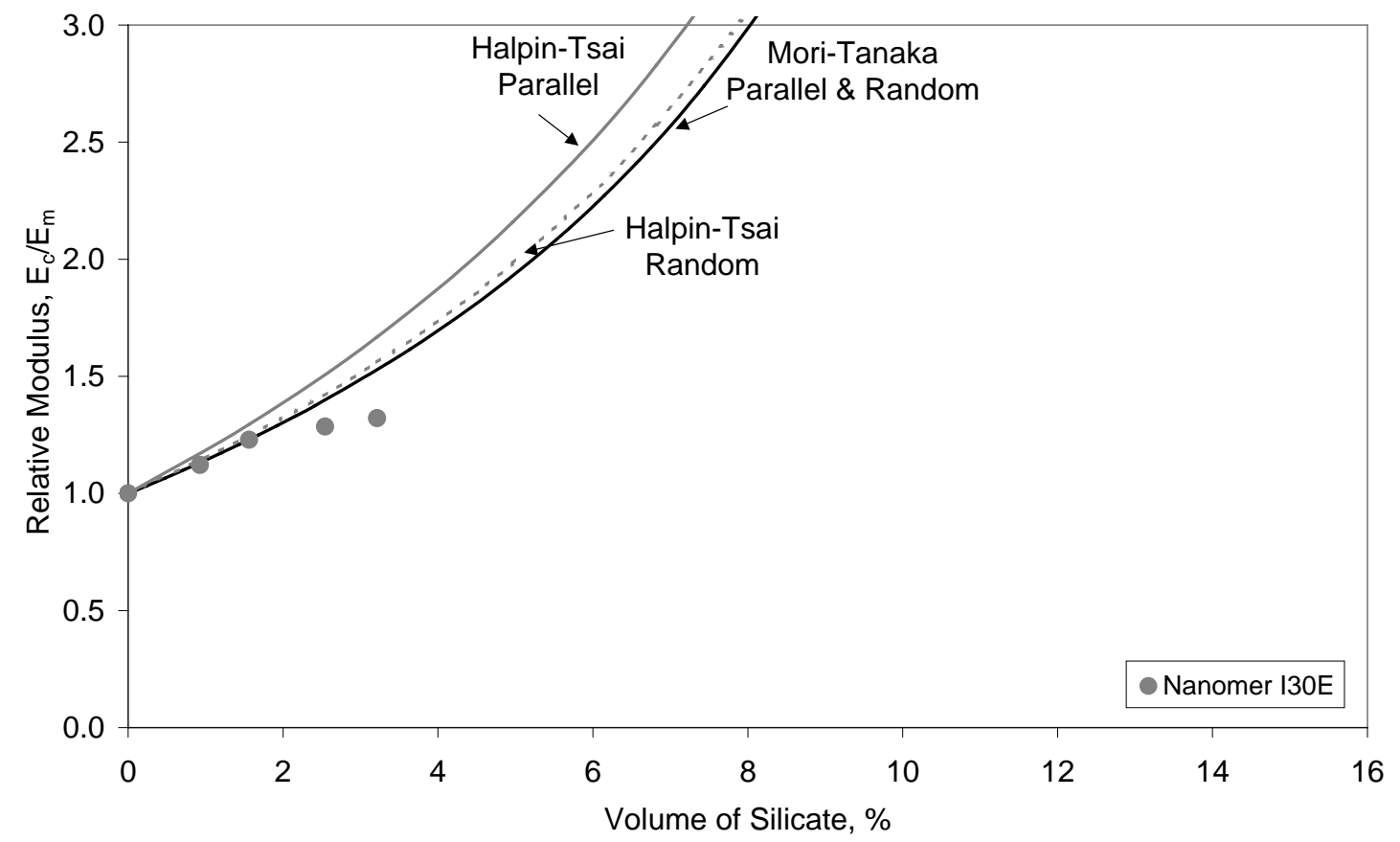

b: Ordered exfoliated nano-composites

Figure 17: Relative modulus (composite modulus divided by unmodified epoxy modulus) versus volume percentage of silicate for a: intercalated nano-composites (random models only), and b: ordered exfoliated nano-composites. Points are experimental data and lines are theoretical predictions. 


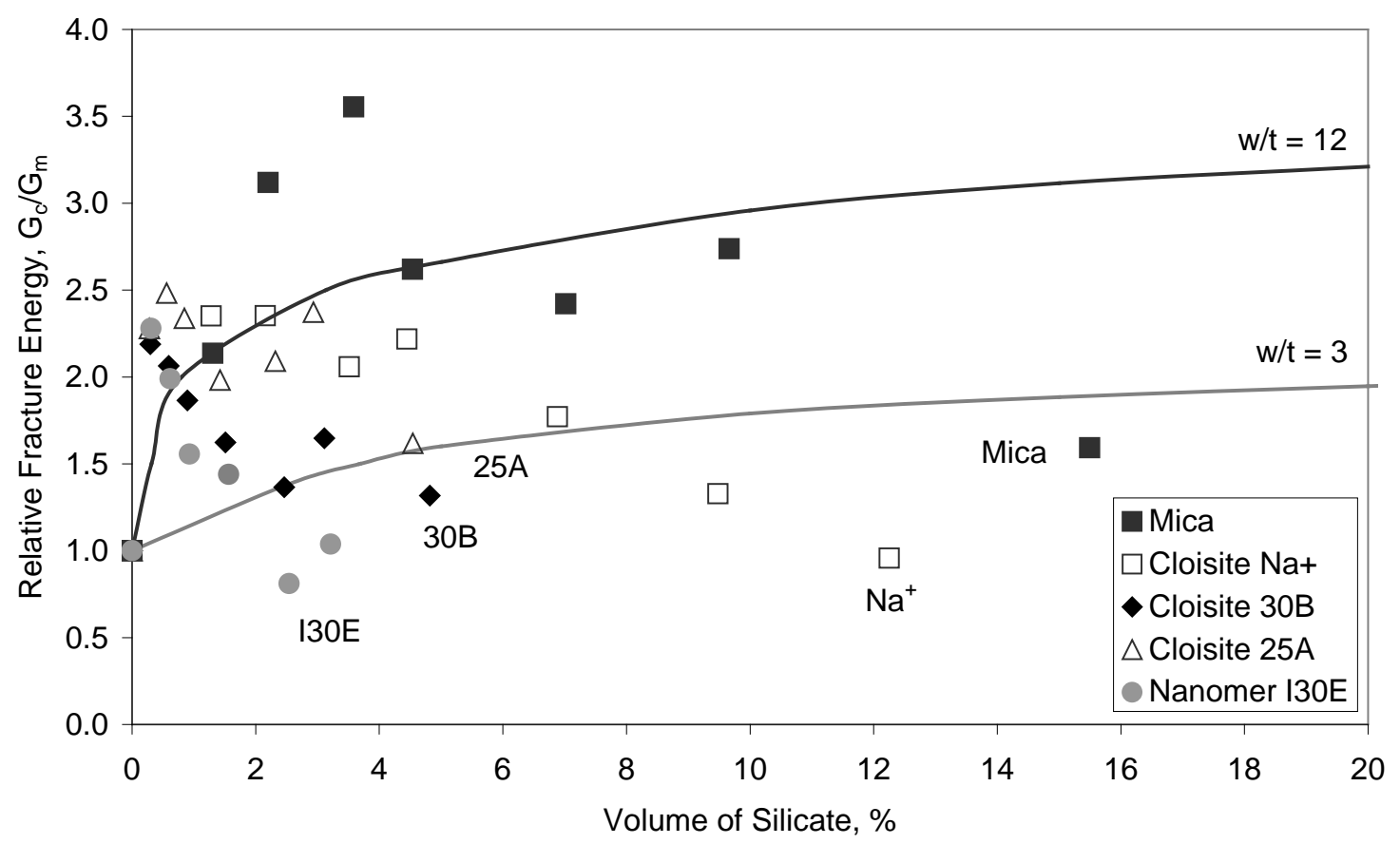

Figure 18: Relative fracture energy (composite fracture energy divided by epoxy-matrix fracture energy) versus volume percentage of silicate for micro- and nano-composites. Points are experimental data and bold lines are theoretical predictions using aspect ratios of twelve and three. $\left(G_{m}=275 \mathrm{~J} / \mathrm{m}^{2}\right.$.) 


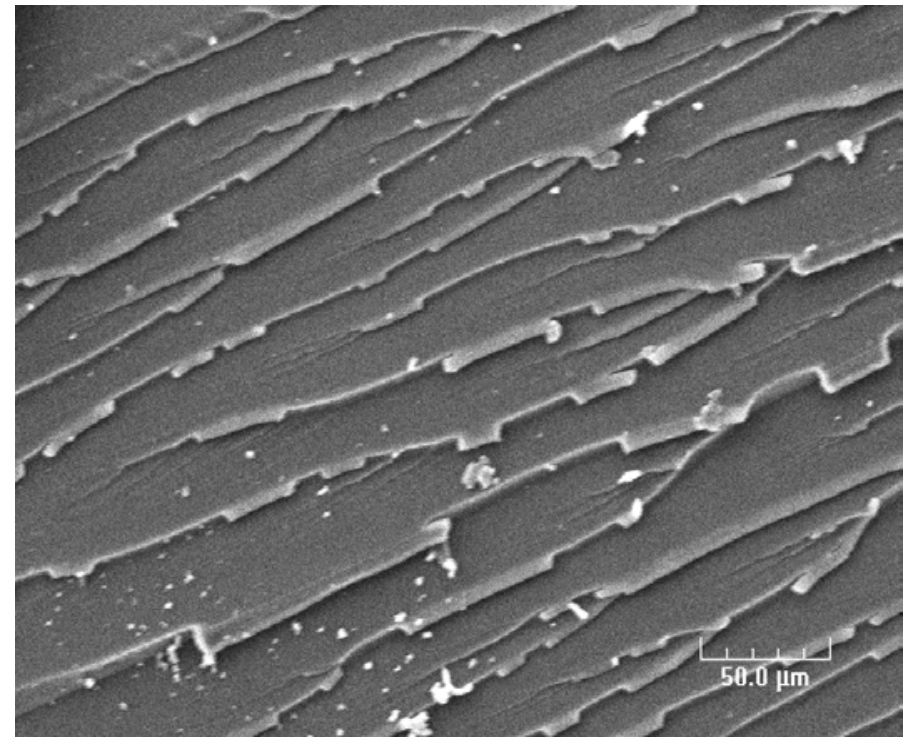

a) Unmodified epoxy.

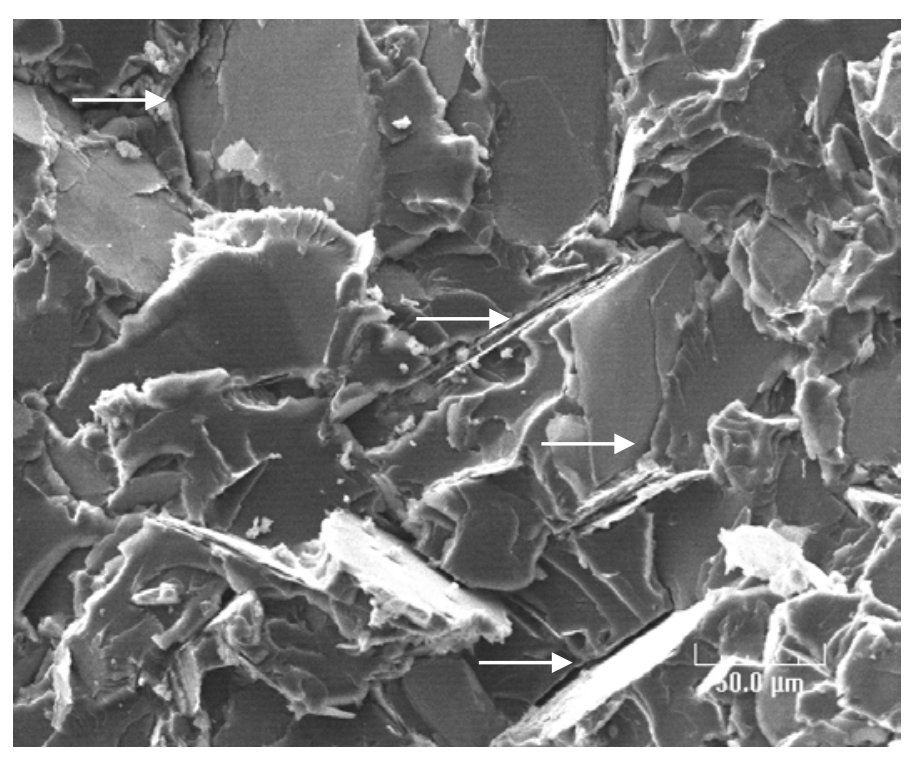

b) 10wt.\% mica. 


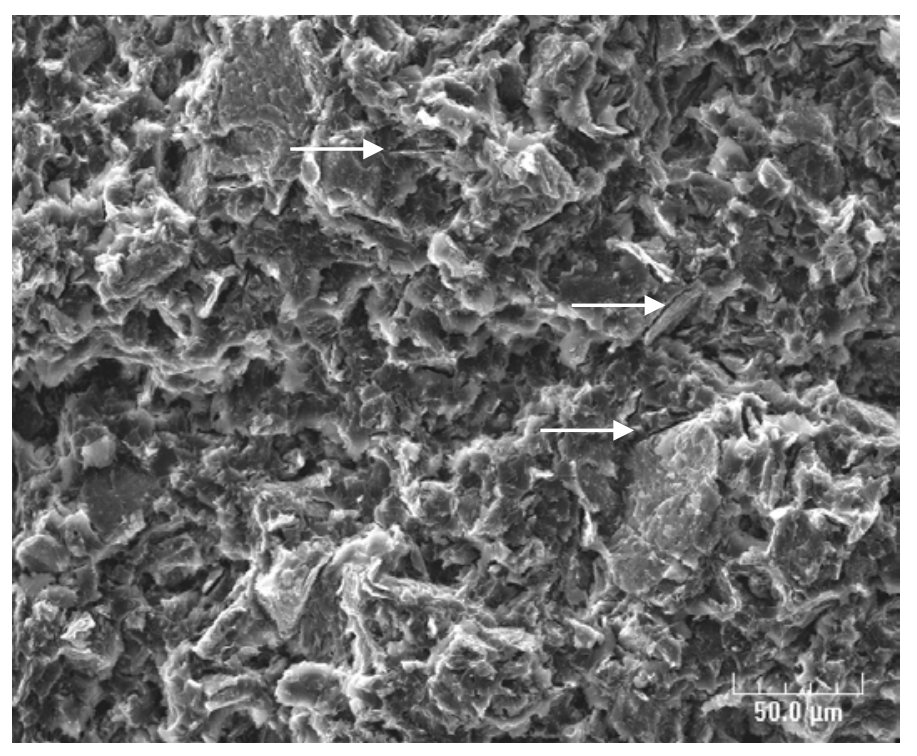

c) $10 \mathrm{wt} . \%$ Cloisite $\mathrm{Na}^{+}$.

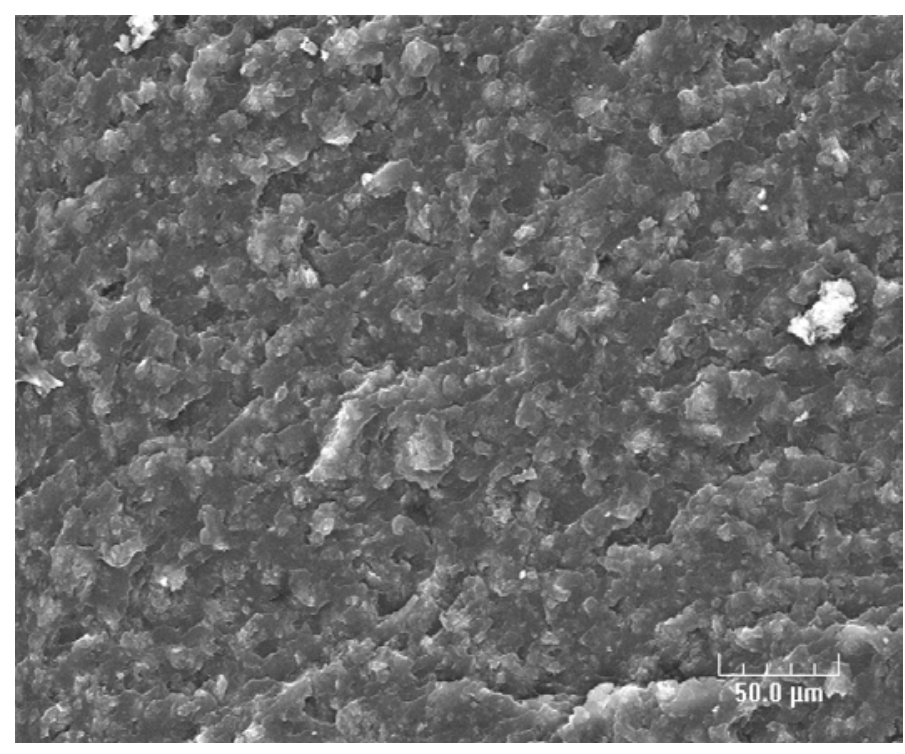

d) 10wt.\% Cloisite 30B.

Figure 19: Scanning electron micrographs of fracture surfaces, a: unmodified epoxy, b: 10wt.\% mica, c: 10wt.\% Cloisite $\mathrm{Na}^{+}$, d: 10wt.\% Cloisite 30B. (Arrows indicate cavities around particles). 


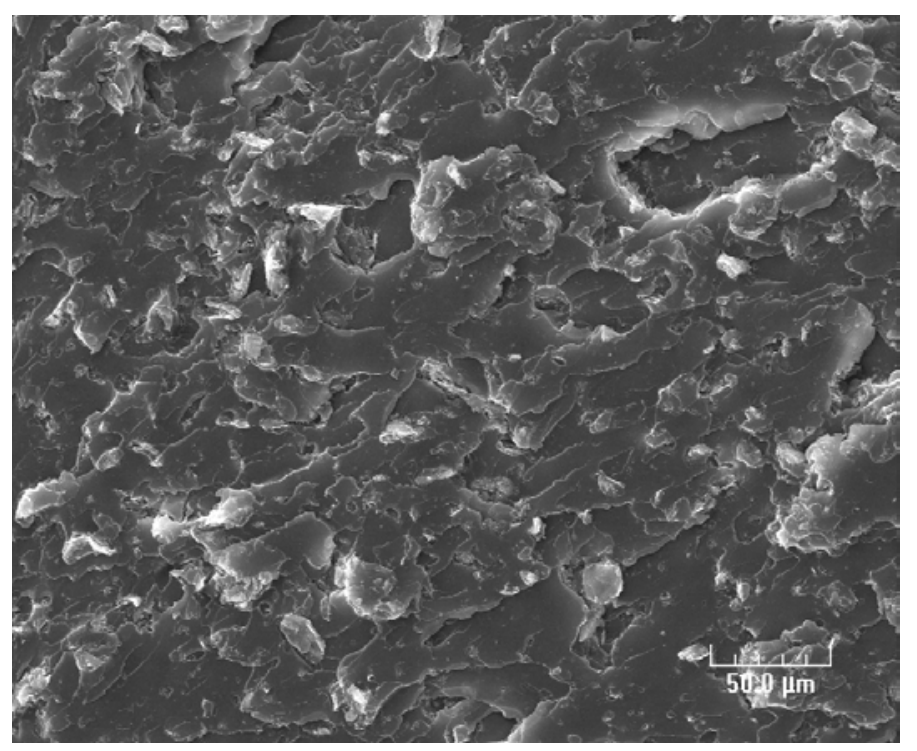

a: 5wt.\% Cloisite $\mathrm{Na}^{+}$

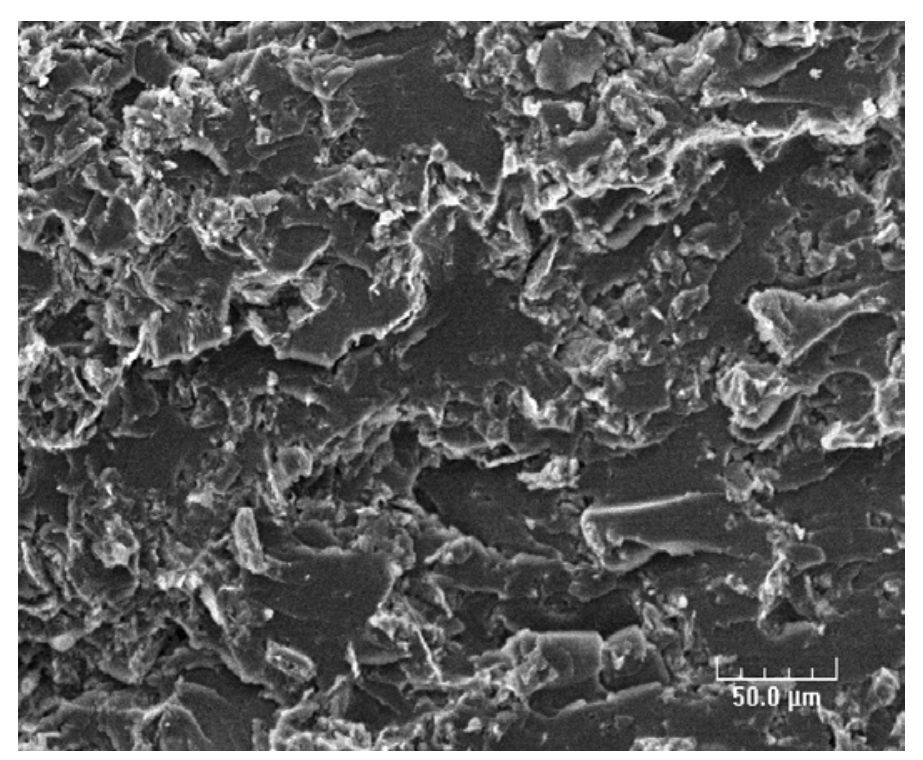

b: 8wt.\% Cloisite $\mathrm{Na}^{+}$ 


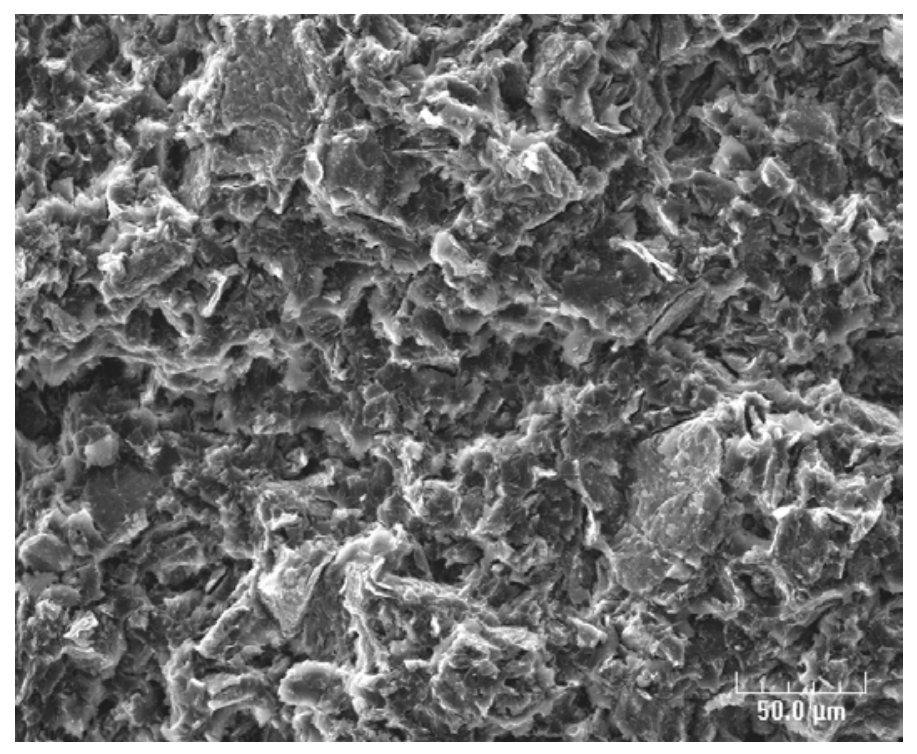

c: 10wt.\% Cloisite $\mathrm{Na}^{+}$

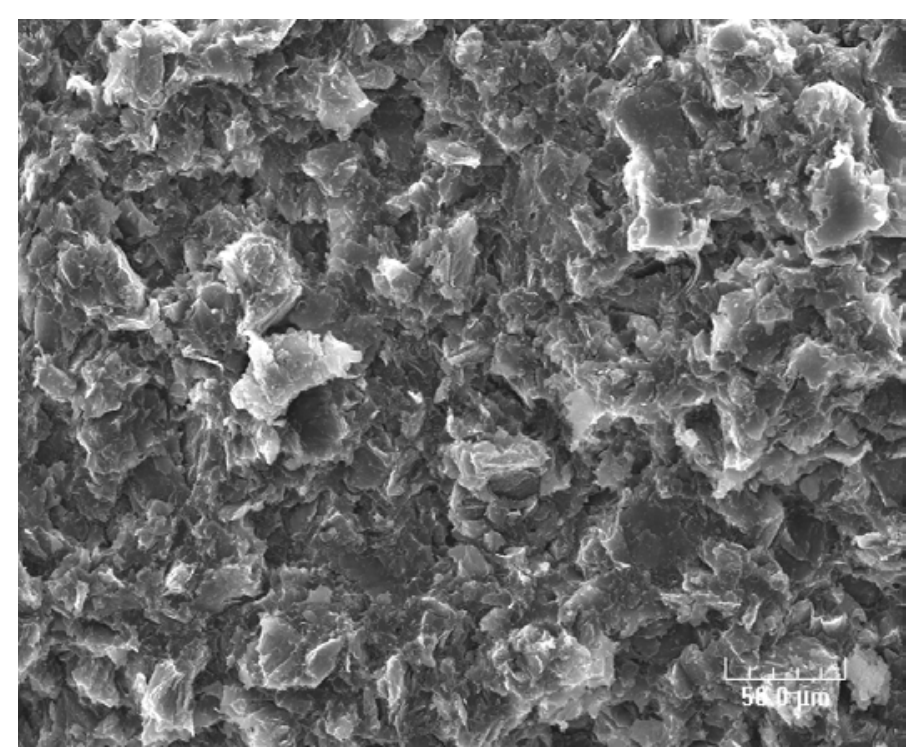

d: 15 wt.\% Cloisite $\mathrm{Na}^{+}$ 


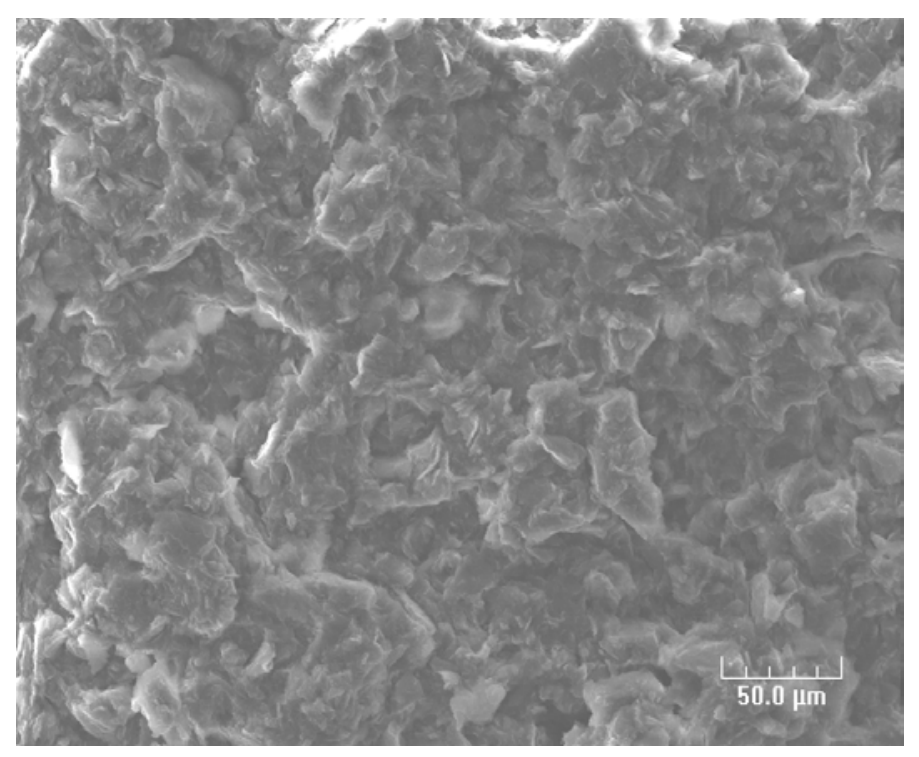

e: 20wt.\% Cloisite $\mathrm{Na}^{+}$

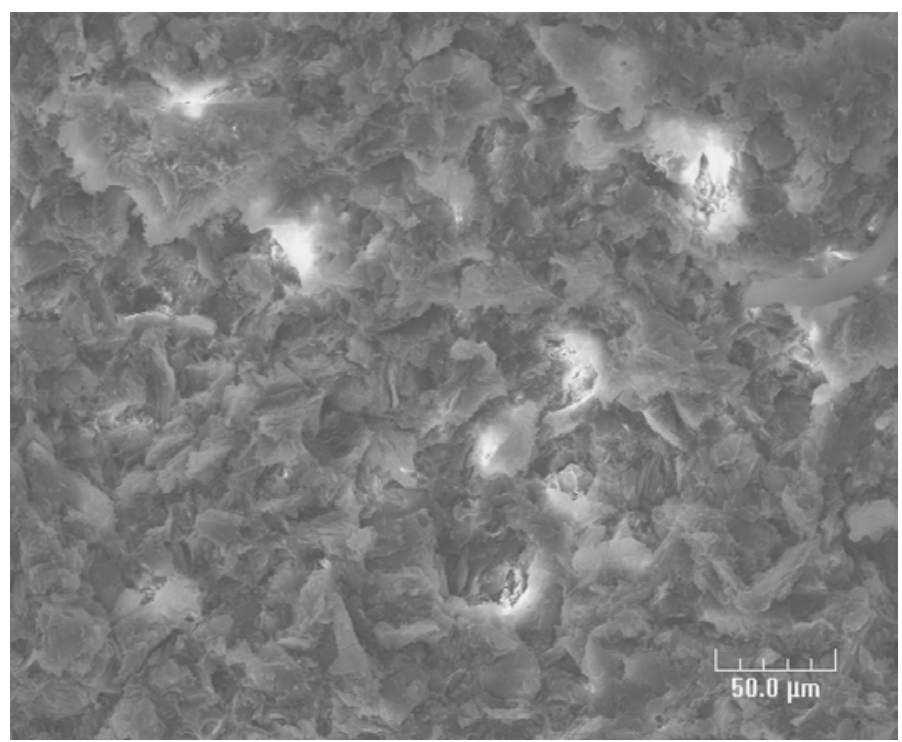

f: 25wt.\% Cloisite $\mathrm{Na}^{+}$

Figure 20: Scanning electron micrographs of fracture surfaces for composites with Cloisite $\mathrm{Na}^{+}$, a: 5wt.\% Cloisite $\mathrm{Na}^{+}$, b: 8wt.\% Cloisite $\mathrm{Na}^{+}$, c: 10 wt.\% Cloisite $\mathrm{Na}^{+}$, d: 15 wt.\% Cloisite $\mathrm{Na}^{+}$, e: 20 wt.\% Cloisite $\mathrm{Na}^{+}$, f: $25 \mathrm{wt} . \%$ Cloisite $\mathrm{Na}^{+}$. 


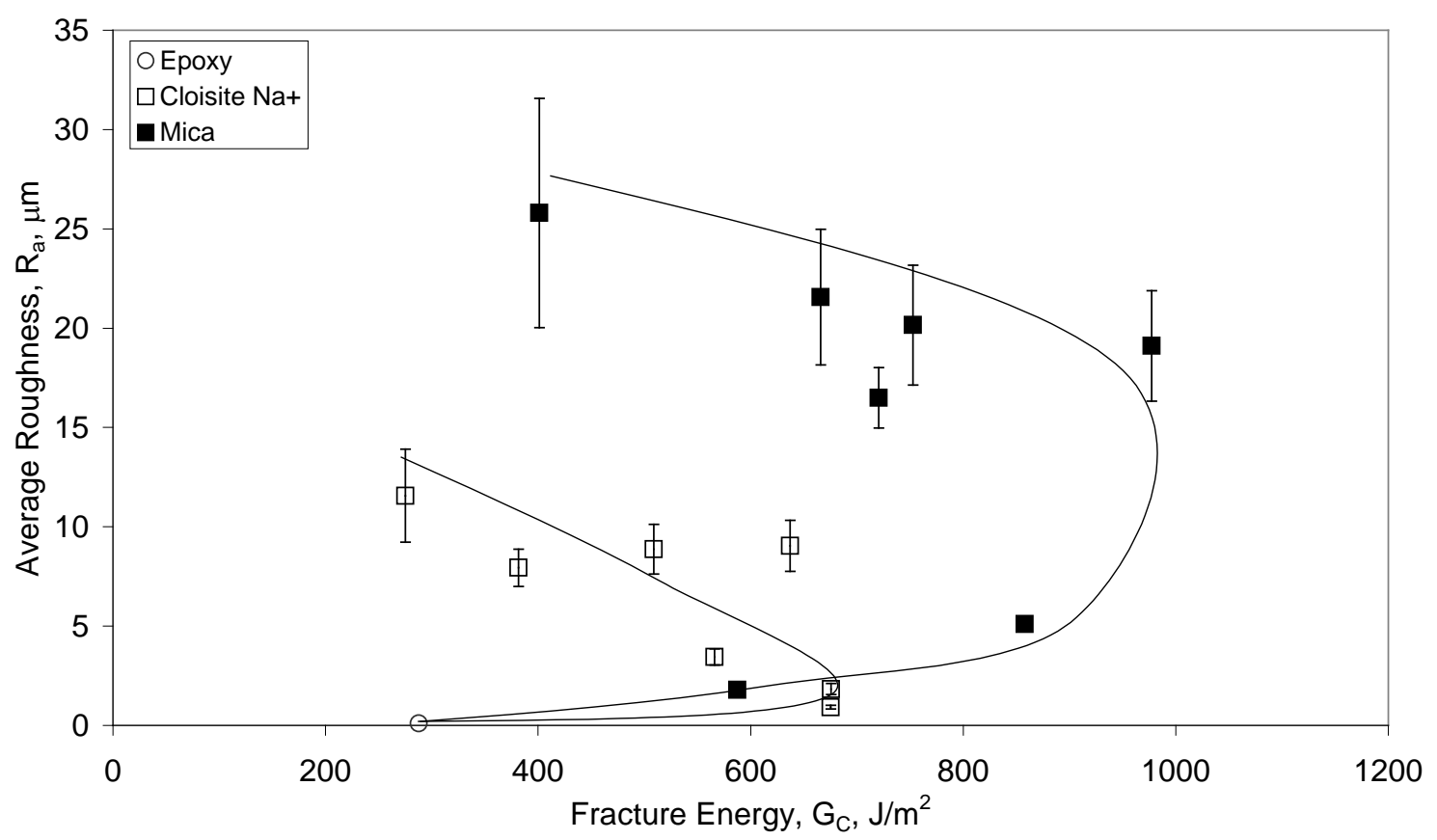

a: Average roughness versus fracture energy for micro-composites

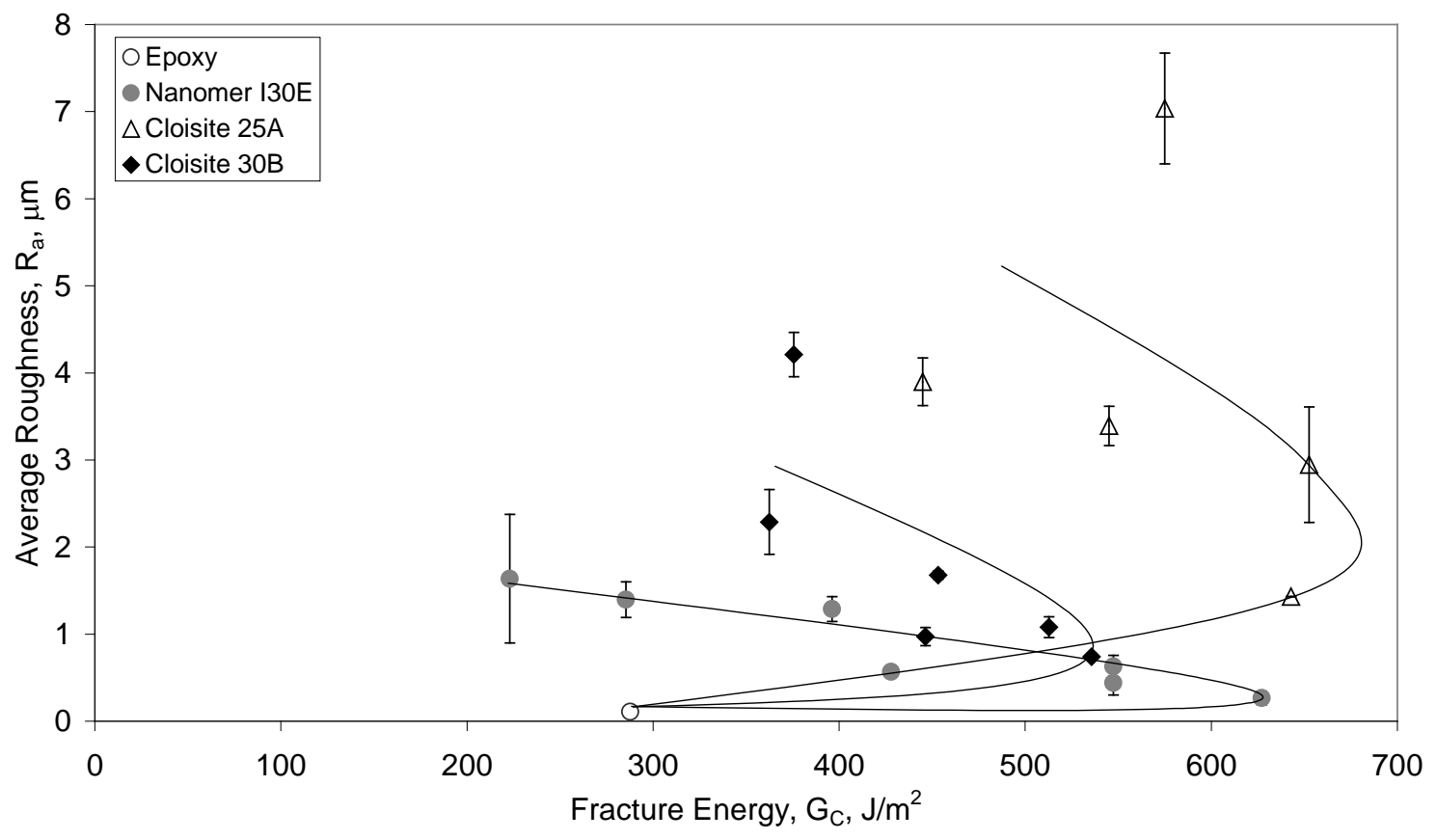

b: Average roughness versus fracture energy for nano-composites 


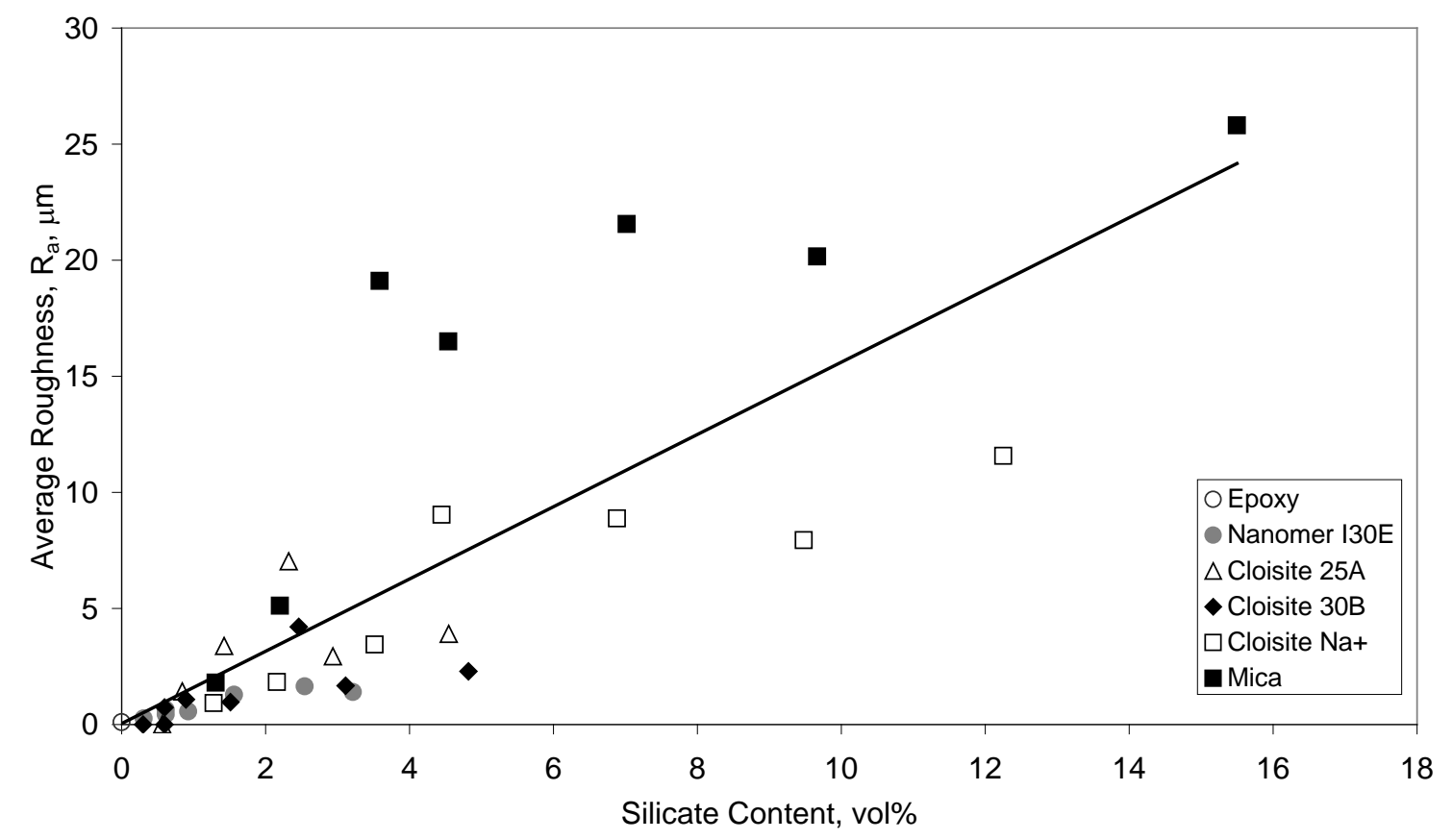

c: Average roughness versus silicate content for all nano- and micro-composites

Figure 21: Average roughness of fracture surfaces versus a: micro-composite fracture energy, b: nanocomposite fracture energy, c: silicate content for all nano- and micro-composites. (Error bars indicate 1 standard deviation). 


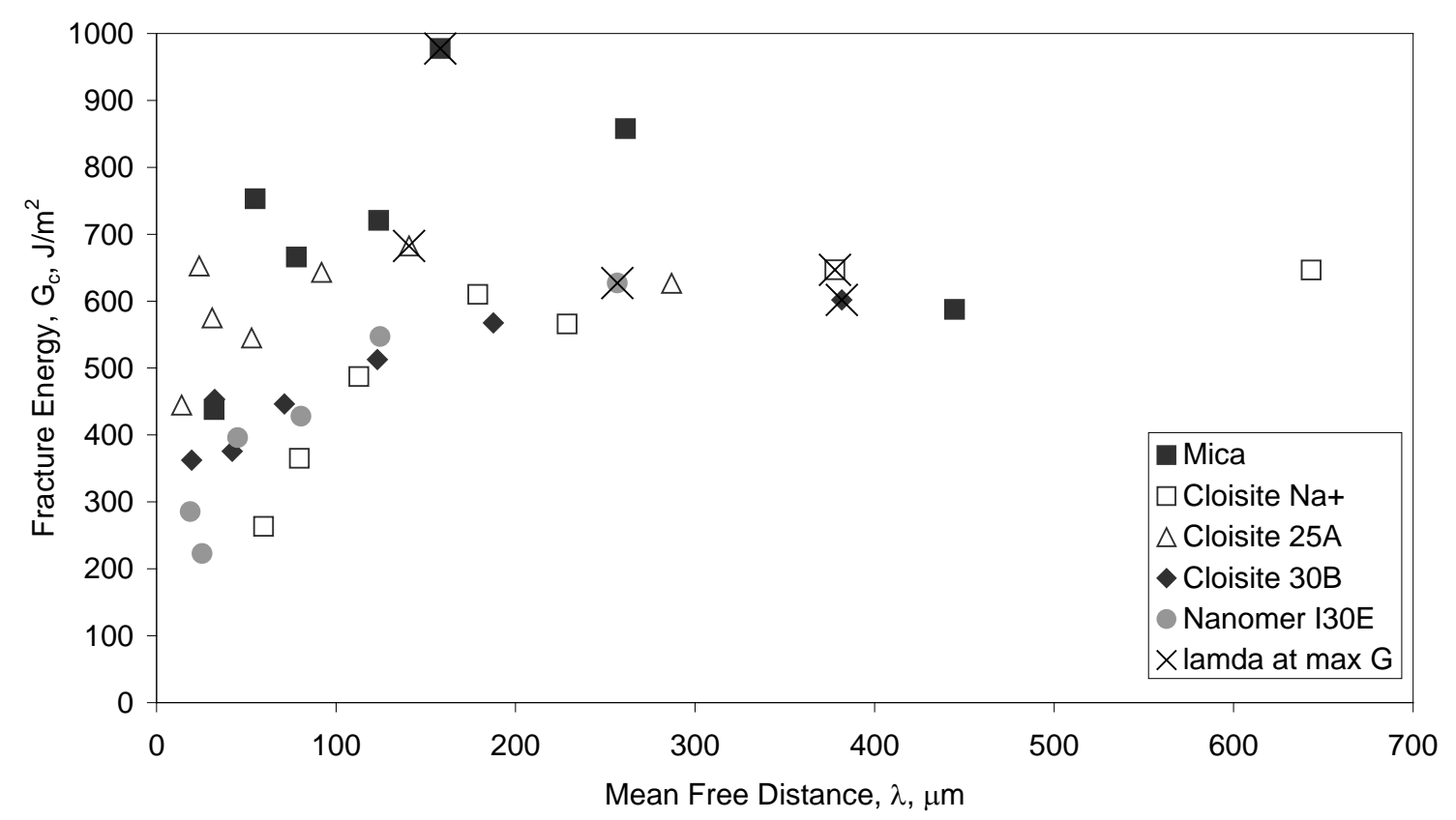

a: Fracture energy versus mean free distance $\left(\right.$ Epoxy $\left.\mathrm{G}_{\mathrm{C}}=275 \mathrm{~J} / \mathrm{m}^{2}\right)$.

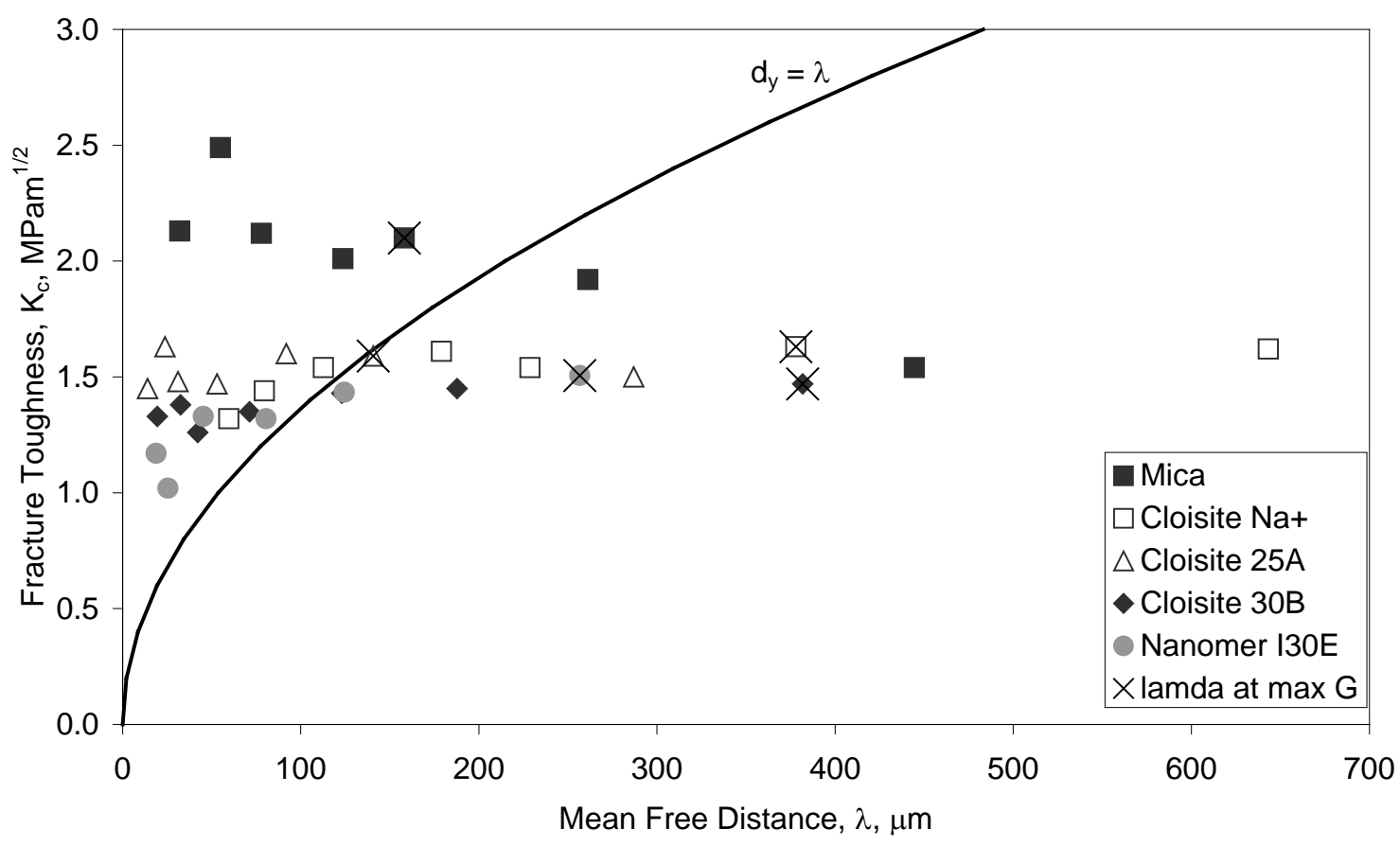

b: Fracture toughness versus mean free distance $\left(\right.$ Epoxy $\left.\mathrm{K}_{\mathrm{C}}=1.0 \mathrm{MPam}^{1 / 2}\right)$.

Figure 22: Effect of interparticle distance between particles for micro- and nano-composites, a: fracture energy versus mean free distance (Epoxy $G_{C}=275 \mathrm{~J} / \mathrm{m}^{2}$ ), b: fracture toughness versus mean free distance $\left(\right.$ Epoxy $\left.\mathrm{K}_{\mathrm{C}}=1.0 \mathrm{MPam}^{1 / 2}\right)$. (Solid line is equivalence of plastic zone size in plane stress with mean free distance.) 